\title{
FRENO DEL TRIBUNAL CONSTITUCIONAL AL ABUSO DEL VETO PRESUPUESTARIO: ANÁLISIS DE LA JURISPRUDENCIA CONSTITUCIONAL EN TORNO AL ART. 134.6. CE
}

ISABEL SAIZ ROS 
SUMARIO

I. INTRODUCCIÓN. II. BREVE APROXIMACIÓN AL RÉGIMEN JURÍDICO CONSTITUCIONAL DEL DENOMINADO VETO PRESUPUESTARIO. 2.1. Supuesto de hecho habilitante: la afectación presupuestaria. 2.2. Ejercicio del veto: la motivación de la disconformidad por parte del gobierno. 2.3. Control del veto: las funciones de la Mesa. III. ANÁLISIS DE LA JURISPRUDENCIA CONSTITUCIONAL EN TORNO AL VETO PRESUPUESTARIO: DE UNA EXÉGESIS DEFICIENTE A UNA SUFICIENTE. 3.1. STC 223/2006, de 6 de julio. 3.2. STC $242 / 2006$, de 24 de julio. 3.3. Consecuencias de esta jurisprudencia constitucional en el ejercicio del veto presupuestario. 3.4. Giro jurisprudencial de la STC 34/2018, de 12 de abril. 3.4.1. Breve panorámica de la jurisprudencia reciente en torno al veto. 3.4.2. STC 34/2018, de 12 de abril. IV. CONCLUSIONES. 


\title{
FRENO DEL TRIBUNAL CONSTITUCIONAL AL ABUSO DEL VETO PRESUPUESTARIO: ANÁLISIS DE LA JURISPRUDENCIA CONSTITUCIONAL EN TORNO AL ART. 134.6. CE
}

\author{
ISABEL SAIZ ROS ${ }^{1}$
}

Universidad de La Laguna

\section{INTRODUCCIÓN}

El art. 134.6 CE reza: «toda proposición o enmienda que suponga aumento de créditos o disminución de los ingresos presupuestarios requerirá la conformidad del Gobierno para su tramitación». El escaso desarrollo legislativo de este precepto lo encontramos en los arts. 111 y 126.2 y 3 del Reglamento del Congreso ${ }^{2}$. En el ámbito autonómico, tan sólo tres son los Estatutos de Autonomía que reproducen el art.134.6

1 Doctoranda en Derecho Constitucional por la Universidad de la Laguna. Departamento de Derecho Constitucional, Camino La Hornera, 37, 38205 San Cristóbal de La Laguna, Santa Cruz de Tenerife. Email: isaizros@gmail.com

2 Art. 126. 2. Ejercitada la iniciativa, la Mesa del Congreso ordenará la publicación de la proposición de ley y su remisión al Gobierno para que manifieste su criterio respecto a la toma en consideración, así como su conformidad o no a la tramitación si implicara aumento de los créditos o disminución de los ingresos presupuestarios. 3. Transcurridos treinta dias sin que el Gobierno bubiera negado expresamente su conformidad a la tramitación, la proposición de ley quedará en condiciones de ser incluida en el orden del día del Pleno para su toma en consideración.

Artículo 111. 1. Las enmiendas a un proyecto de ley que supongan aumento de los créditos o disminución de los ingresos presupuestarios requerirán la conformidad del Gobierno para su tramitación. 2. A tal efecto, la Ponencia encargada de redactar el informe, remitirá al Gobierno, por conducto del Presidente del Congreso, las que a su juicio puedan estar incluidas en lo previsto en el apartado anterior. 3. El Gobierno deberá dar respuesta razonada en el plazo de quince días, transcurrido el cual se entenderá que el silencio del Gobierno expresa conformidad. 4. El Gobierno podrá manifestar su disconformidad con la tramitación de enmiendas que supongan aumento de los créditos o disminución de los ingresos presupuestarios en cualquier momento de la tramitación, de no haber sido consultado en la forma que señalan los apartados anteriores. 
CE: el Estatuto de Extremadura (art. 190 EAE), el de Andalucía (art. 78.7 EAA) y el de Valencia (75.1 EACV). Sin embargo, todos y cada uno de los Reglamentos parlamentarios autonómicos contemplan esta prerrogativa gubernamental, comúnmente denominada veto presupuestario ${ }^{3}$. Estamos pues ante una facultad reconocida a los Gobiernos estatal y autonómico de no prestar su conformidad a la tramitación de aquellas enmiendas y proposiciones de ley que impliquen un aumento de gasto o una disminución de ingresos presupuestarios.

Como toda prerrogativa del Gobierno, el tema ha suscitado y suscita interés, puesto que el hecho de que un Ejecutivo posea en sus manos un instrumento de limitación legislativa no parece cuadrar a primera vista con la visión idealista del parlamentarismo. Parlamentarismo ideal que nunca existió ni existe pero que, queramos o no, continúa en nuestro imaginario colectivo ${ }^{4}$. De hecho, tal y como reconoce Giménez Sánchez, los propios Gobiernos son conscientes de la mala imagen que el uso de esta prerrogativa podría acarrearles, por lo que, contando con el apoyo de la mayoría en la Cámara, «en la práctica parlamentaria española lo normal ha sido que los sucesivos ejecutivos hayan evitado la utilización de esta facultad» ${ }^{5}$. Esto es, bastaba con que la mayoría parlamentaria progobierno votara en contra de la iniciativa o enmienda, no teniendo la necesidad de recurrir el ejercicio del veto presupuestario para llevar a cabo su programa de gobierno.

3 Tal como señala Marrero García-Rojo, A., la expresión «veto presupuestario» la utilizan por primera vez García Morillo J. y Pérez Tremps, P. [(1998) «Legislativo versus ejecutivo autonómicos, el problema del control del veto presupuestario». Parlamento y Constitución. Anuario, no 2, pp. 9-44]. Pero «su aceptación por parte de la doctrina y de la jurisprudencia nos lleva a utilizarla aquí». Marrero GarcíaRojo, A. (2007). «El control del ejercicio por el Gobierno de la facultad de veto presupuestario (Comentario a la STC 223/2006, con consideración de la STC 242/2006)». Revista española de derecho constitucional, No 80, p.314.

4 Cfr. García Morillo, J. (1991). «Mitos y realidades del parlamentarismo». Revista del Centro de Estudios Constitucionales y Políticos, n 9, pp. 117-120: (...) «Conveniente preguntarse si la idea que generalmente se tiene del Parlamento se corresponde con la realidad. Resumiéndola sintéticamente, esa «idea general» se podría traducir en que el Parlamento debe ser el elemento central del sistema, aquel en el que se centrípeta toda la vida política, en el que se recogen los intereses sociales de la ciudadanía y se busquen y encuentren soluciones a los problemas que plantea la satisfacción de dichos intereses. Igualmente, el Parlamento debería ser, además de lo anterior, eficaz, es decir, un órgano susceptible de actuar con rapidez, precisión técnica e imaginación política. Por otro lado, las sesiones parlamentarias deben iniciarse bajo el signo de la duda, en la mayor incertidumbre posible de cual vaya a ser el transcurso de la sesión y de a quién sonreirá la victoria en caso de votación final: esta imagen ideal exige que las intervenciones de los parlamentarios consigan efectivamente convencer a sus oponentes y cambiar el sentido de sus votos. En fin, el Parlamento debería ser capaz de modificar la actuación del Gobierno y de los demás poderes públicos y de remover al Gobierno cuando no considere satisfactoria su actividad. No parece necesario un gran esfuerzo para demostrar que este modelo de «Parlamento ideal» nunca existió, ni siquiera en los albores de la configuración del parlamentarismo. Hasta tal punto es así que la difusión de ese supuesto «modelo ideal» de Parlamento se aleja de la utilización del manejo teorético de los tipos ideales como método de trabajo científico y se introduce en la manipulación ideológica».

5 Giménez Sánchez, I. (2017). «El significado de la conformidad del Gobierno a las proposiciones de ley por aumento de créditos o disminución de ingresos». Coord. por Aranda Álvarez, E., Lecciones constitucionales de 314 dias con el Gobierno en funciones, Valencia, Tirant lo Blanch, p.287. 
Por tanto, en un principio el interés fue más teórico que práctico: la doctrina se preguntaba cuál era en último término el fundamento de esta facultad, y cuál era la interpretación correcta del apartado sexto del art.134 CE. Asimismo, las polémicas SSTC 223/06, de 6 de julio y 242/06, de 24 de julio dieron también lugar a abundante bibliografía sobre el tema, generalmente en clave de crítica al Tribunal por no haber acogido la doctrina mayoritaria y convertir el veto presupuestario en una facultad incondicionada y libre del Gobierno.

Pero el problema en cuanto a su uso desmedido por parte del Ejecutivo se inició con el cambio de las circunstancias políticas que se produjeron, primeramente, a raíz de las elecciones de diciembre de 2015 -que dieron lugar a una corta legislatura fallida de seis meses- y posteriormente y de modo ya definitivo, en las de junio de 2016. El resultado de dichas elecciones fue una Cámara fragmentada y un Gobierno sin apoyos suficientes para aprobar y frenar cuantas iniciativas legislativas deseara. Todo ello propició un uso tan reiterado por parte del Gobierno que es digno de ser calificado no ya de abuso, sino de corruptela parlamentaria (abusus non est usus, sed corruptela). En la XII legislatura el Gobierno de Rajoy lo ejercitó hasta en cincuenta y tres ocasiones, concurriera o no el presupuesto de hecho habilitante para el ejercicio del veto ${ }^{6}$. Este ejercicio repetitivo suscitó varios conflictos entre ambos poderes — Legislativo y Ejecutivo- que fueron elevados al Tribunal Constitucional como conflictos de atribuciones o conflictos entre órganos constitucionales (art. 73 LOTC), dando lugar a sendas sentencias: la STC 34/2018, de 12 de abril, y la STC 44/2018, de 20 de abril. Asimismo, dadas las consecuencias que en el ámbito de los derechos de los parlamentarios tiene el uso desmedido del veto — pues puede conllevar una limitación del ius in officium de los parlamentarios (art. $23 \mathrm{CE}$ )— fueron tres los recursos de amparo (art. 41 LOTC) interpuestos ante el Tribunal Constitucional, que dieron lugar a las SSTC 94/2018 de 12 de octubre, 139/2018, de 17 de diciembre y 17/2019, de 19 de marzo.

El presente artículo tiene por objeto el análisis de la jurisprudencia constitucional en torno al veto presupuestario. Por el papel de intérprete supremo que ejerce el Tribunal Constitucional (art. 1 LOTC), «su interpretación (...) es la última o definitiva. Ese carácter de supremo intérprete de la Constitución hace del Tribunal Constitucional la pieza fundamental de nuestro ordenamiento» ${ }^{7}$. Y pieza fundamental ha sido, a través de su reciente jurisprudencia, en la tarea de clarificación de este precepto constitucional. Si en un principio pensamos no llevó a cabo de modo satisfactorio su labor interpretativa, las últimas sentencias contienen unos criterios que podríamos calificar de suficientes y adecuados. (v. §III. Análisis de la jurisprudencia constitucional en torno al veto presupuestario: de una exégesis deficiente a una suficiente).

Haremos en un primer momento un breve resumen del régimen jurídico del veto presupuestario, para analizar después pormenorizadamente la jurisprudencia consti-

6 Para mayor abundamiento y datos concretos: v. \$3.3. Las consecuencias de esta jurisprudencia constitucional en el ejercicio del veto presupuestario, p. 276 en adelante.

Aragón Reyes, M., (1998). Estudios de derecho constitucional. Madrid, Centro de Estudios Políticos y Constitucionales, p.310. 
tucional, profundizando en los distintos enfoques y perspectivas que llevan al Tribunal a interpretar en uno u otro sentido, y concluyendo en la importancia de adoptar una visión adecuada de esta figura jurídica para poder interpretarla correctamente.

\section{BREVE APROXIMACIÓN AL RÉGIMEN JURÍDICO CONSTITUCIONAL DEL DENOMINADO VETO PRESUPUESTARIO}

Cuando hablamos de régimen jurídico constitucional nos referimos a la regulación que contiene o que se deriva de este apartado sexto del $134 \mathrm{CE}$; al sistema de funcionamiento que establece, a las reglas que se deducen de este precepto. Se trata de esclarecer qué dice la Constitución en este punto sobre el modo y las condiciones de ejercicio legítimo de la facultad de veto, o por el contrario, qué no dice y qué prohíbe, más o menos explícitamente. Las preguntas a responder son: en este precepto, donde se consagra la facultad del Gobierno de no prestar su conformidad a aquellas proposiciones o enmiendas que supongan un aumento de gastos o una disminución de ingresos presupuestarios, ¿qué sistema establece nuestra Constitución y cómo regula el funcionamiento de dicha facultad? Es decir, en primer lugar: ¿qué supuestos de hecho se subsumen bajo esta figura, de tal manera que el Gobierno, en dichos casos, esté facultado — constitucionalmente- para no prestar su anuencia a tales iniciativas legislativas? Y en segundo lugar: ¿de qué modo ha de ejercitarse dicha facultad gubernamental para que su ejercicio — una vez permitido — pueda ser calificado de legítimo? Pensamos que éstas son las dos cuestiones a clarificar: cuál es el supuesto de hecho habilitante de la facultad de veto y cómo debe ejercitarlo el Gobierno. Además, sobre esa conformidad, el Reglamento del Congreso habilita a la Mesa a ejercer cierto control, constituyendo éste el tercero de los elementos que configuran la facultad del veto gubernamental.

Dicho lo cual, estamos de acuerdo con Marrero García-Rojo, cuando afirma que el veto presupuestario posee dos elementos esenciales: el primero sería la concurrencia del requisito del efecto o repercusión presupuestaria y el segundo la estricta declaración de voluntad del Gobierno expresando su disconformidad a la tramitación de la enmienda o proposición de ley ${ }^{8}$. Así lo entiende también Giménez Sánchez, quien además de recoger la idea de este autor, entiende el primero de los dos elementos esenciales como «supuesto de hecho habilitante» de la facultad gubernamental ${ }^{9}$. En general, la mayoría de la doctrina comprendió muy bien desde el principio esta distinción entre el supuesto de hecho habilitante y la manifestación de la voluntad del Gobierno en forma de disconformidad a la tramitación de la proposición o enmienda correspondiente.

8 Marrero García-Rojo, A., op. cit., pp.314 y 323.

9 Giménez Sánchez, I. (2017). «El control del Parlamento sobre el llamado «veto presupuestario» del Gobierno». Revista jurídica de Castilla y León, $\mathrm{n}^{\circ}$ 42, p.97. 


\subsection{Supuesto de hecho habilitante: la afectación presupuestaria.}

Para que el Gobierno pueda negar su consentimiento al trámite de alguna iniciativa legislativa, deben darse toda una serie de hechos objetivos que constituyen el supuesto de hecho habilitante para el ejercicio del veto.

El primero de ellos se refiere al marco temporal, respecto al cual «la totalidad de la doctrina (...) entiende que el veto presupuestario sólo es oponible como instrumento de defensa del equilibro del Presupuesto en curso ${ }^{10}$. Además, la iniciativa legislativa en cuestión debe producir efectivamente un aumento de los gastos presupuestarios o una disminución de los ingresos. No es ésta una decisión discrecional del Gobierno, quien no puede decidir si tal afectación presupuestaria se produce, sino un hecho del todo objetivo, pues la iniciativa legislativa debe afectar a concretas partidas presupuestarias del ejercicio en curso, bien produciendo un aumento de alguna partida de gastos, bien una disminución de alguna partida de ingresos. El ejercicio del veto estará justificado si tales iniciativas legislativas resultan contrarias a la orientación económica del Ejecutivo, si existen una vinculación entre las mismas y el Presupuesto en vigor ${ }^{11}$.

En resumen, la conexión que debe existir entre la iniciativa legislativa eventualmente objeto del veto y la Ley de Presupuesto debe estar adornada de las siguientes virtudes: debe ser una conexión directa, inmediata, real, efectiva y actual ${ }^{12}$.

De este modo entendemos que ha de interpretarse la expresión «toda proposición o enmienda que suponga aumento de los créditos o disminución de los ingresos presupuestarios» contenido en el art. 134.6 CE.

\subsection{Ejercicio del veto: la motivación de la disconformidad del Gobierno.}

Hablamos aquí de la interpretación del «requerirá la conformidad del Gobierno para su tramitación», contenido en el art. 134.6 CE. Esto es, el Gobierno está habilitado, por mandato constitucional, a oponerse a la tramitación de aquellas proposiciones o enmiendas que, efectivamente, supongan un incremento de los gastos o una disminución de los ingresos presupuestarios.

Una vez se dé el supuesto de hecho habilitante, es decir, que la afectación al Presupuesto en curso de la iniciativa legislativa en cuestión sea directa, inmediata, real y actual, el Gobierno entonces, y sólo entonces, está en condiciones de negar su aquiescencia a la tramitación de la misma. Pero en cualquier caso, ya estemos ante un

10 García Morillo, J., y Pérez Tremps, P., op. cit., p.21.

11 Delgado Ramos, D. (2019). «El veto presupuestario del Gobierno». Revista de Estudios Políticos, $\mathrm{n}^{\circ} 183, \mathrm{p} .87$.

12 Escribano López, F. (2018). «Acerca del régimen jurídico constitucional de las proposiciones de ley que impliquen aumento de gasto o disminución de ingresos presupuestados (Un comentario a las SSTC 34/2018 y 44/2018)». Revista española de derecho financiero, nº 180, p.197. 
caso de afectación real al presupuesto en vigor, ya ante uno de ausencia, es el Gobierno quien tiene la «carga de la prueba», pues debe motivar que se dan todas las condiciones y elementos requeridos para un uso legítimo de su facultad de veto.

De este modo, como dice Escribano López, «la disconformidad gubernamental debe ser suficientemente motivada, a fin de que pueda verificarse la efectiva conexión de la medida objeto de debate con los ingresos y gastos presupuestados del Presupuesto en ejecución. El Tribunal Constitucional lo formula con precisión: el presupuesto habilitante de la disconformidad gubernamental no es otro que la estricta vinculación de la norma presupuestaria en vigor, es decir, a la correspondiente al Presupuesto que se está ejecutando, nunca a un presupuesto futuro, pues supondría (...) un menoscabo de las competencias de la Cámara proyectadas en el tiempo» ${ }^{13}$.

Pero una vez constatada la afectación presupuestaria, el Gobierno es plenamente libre de ejercer o no el veto, no pudiendo nadie sustituir al Gobierno en esta decisión, ni siquiera el propio Tribunal Constitucional ${ }^{14}$.

\subsection{Control del veto: las funciones de la Mesa.}

Una vez el Gobierno ejercite el veto, la Mesa tiene el papel principalísimo de controlar que tal ejercicio ha sido legítimo. Esto es, la Mesa ha de examinar la motivación del Gobierno, debiendo constatar que se ha justificado por el Gobierno que concurre el supuesto de hecho habilitante contenido en la norma constitucional, esto es, la disminución de los ingresos o el aumento de los créditos presupuestarios.

Es decir, el objeto de control de la Mesa es, exclusivamente, la motivación del Gobierno, no pudiendo ir más a allá en su control, en el sentido de que no puede ella llevar a cabo una labor de análisis de la repercusión presupuestaria de la iniciativa, directamente y con independencia del criterio del Gobierno. No se trata de verificar por su cuenta que se da el supuesto de hecho habilitante: esa es tarea del Gobierno. La Mesa analiza esta labor realizada por el Gobierno, comprobando que la justificación alegada por él es lo suficientemente razonable y verosímil como para frenar una iniciativa legislativa parlamentaria. Por ello, la Mesa podría «decidir continuar con la tramitación de la iniciativa sobre la que el Gobierno no ha mostrado su conformidad, si considera infundada la apreciación realizada por el Ejecutivo. En caso contrario, se estaría permitiendo que un Gobierno pudiera llegar a coartar cualquier propuesta no proveniente de la mayoría parlamentaria» ${ }^{15}$.

13 Ídem.

14 Giménez Sánchez, I. (2017). «El control del Parlamento sobre el llamado «veto presupuestario» del Gobierno». Revista jurídica de Castilla y León, no 42, p.97.

15 Giménez Sánchez, I., (2017). «El significado de la conformidad del Gobierno a las proposiciones de ley por aumento de créditos o disminución de ingresos». Coord. por Aranda Álvarez, E., Lecciones constitucionales de 314 días con el Gobierno en funciones, Valencia, Tirant lo Blanch, p.292.

Pensamos que más que de «mayoría parlamentaria», parece más correcto hablar de «fuerzas parlamentarias progubernamentales», pues es perfectamente posible que la mayoría parlamentaria 


\section{ANÁLISIS DE LA JURISPRUDENCIA CONSTITUCIONAL EN TORNO AL VETO PRESUPUESTARIO: DE UNA EXÉGESIS DEFICIENTE A UNA SUFICIENTE}

Hasta el año 2018, la jurisprudencia del Tribunal Constitucional en torno al veto presupuestario se reducía a dos sentencias, dictadas ambas en el año 2006 y en el ámbito autonómico. La primera de ellas, la STC 223/06, resolvió un recurso de inconstitucionalidad y la segunda, la STC 242/06, un recurso de amparo. Aunque se ha escrito mucho sobre ambas, conviene resumir brevemente los principales argumentos esgrimidos por nuestro Alto Tribunal, así como las críticas más relevantes sobre su jurisprudencia manejadas por la doctrina.

\subsection{STC 223/06, de 6 de julio.}

Centrándonos en la STC 223/06, el recurso de inconstitucionalidad (art. 31 LOTC) fue interpuesto por el Consejo de Gobierno de la Junta de Extremadura y por ochenta y un Senadores del Grupo Socialista, contra los arts. 111.1 (párrafo segundo) y 121.4 (párrafo segundo) ${ }^{16}$ que se proponían en la reforma del Reglamento de la Asamblea de Extremadura de 29 de mayo de 1997. Entendían los recurrentes que la reforma propuesta contravenía el art. 61 b) del Estatuto de Autonomía de Extremadura $(\mathrm{EAE})^{17}$, «pues supone[n] una alteración radical del sistema de relación entre el Ejecutivo y la Asamblea diseñado» en dicho artículo. El origen de la reforma, como recoge la misma sentencia (FJ4), está en la disconformidad — que adolecía de falta de motivación según la Mesa - de la Junta de Extremadura a la tramitación de doce proposiciones de ley presentadas por grupos parlamentarios de la oposición durante

(relativa o absoluta de la investidura) torne en más o menos hostil para el Gobierno según el momento y la circunstancia política.

16 Art. 111.1.- «Las enmiendas a un proyecto de Ley que supongan aumento de los créditos o disminución de los ingresos presupuestarios del ejercicio en curso requerirán la conformidad de la Junta de Extremadura para su tramitación. Cuando la disconformidad de la Junta de Extremadura sea manifiestamente infundada y no exista coincidencia con la interpretación que haga la Mesa de la Asamblea, decidirá el Pleno de la Cámara, en un debate de los de totalidad, en la primera sesión plenaria que se celebre, oída previamente la Junta de Portavoces».

Art. 121.4.- "Conocido el criterio de la Junta de Extremadura que supusiera la oposición a la tramitación por implicar la iniciativa aumento de los créditos o disminución de los ingresos presupuestarios, la Mesa de la Asamblea acordará la no admisión a trámite de la proposición de Ley y la devolución a su autor.

Cuando la disconformidad de la Junta de Extremadura sea manifiestamente infundada, decidirá el Pleno de la Cámara, tras un debate de los de totalidad, en la primera sesión plenaria que se celebre, a propuesta de la Mesa, oída la Junta de Portavoces. Dicho debate versará únicamente sobre la discrepancia de criterios sobre si la iniciativa supone o no aumento de los créditos o una disminución de los ingresos presupuestarios en vigor».

17 Art. 61 b) de la Ley Orgánica 1/1983 de 25 de febrero del Estatuto de Autonomía de Extremadura: "Corresponde a la Junta de Extremadura, sin perjuicio de lo dispuesto en el artículo anterior y concordantes de este Estatuto: la conformidad para tramitar toda proposición o enmienda que suponga aumento de los créditos o disminución de los ingresos presupuestarios». 
la IV legislatura. Ciertamente el propio EAE recoge en su artículo 61 b) la posibilidad que tiene la Junta de no prestar su conformidad a la tramitación de enmiendas y proposiciones de ley que supongan un aumento de los créditos o una disminución de los ingresos presupuestarios. Mediante la reforma del Reglamento se pretendía evitar el uso abusivo del veto, reservando al Pleno de la Cámara la resolución de los eventuales conflictos entre la Junta y la Mesa de la Asamblea. Esto es, en los casos en los que la Mesa considere que la disconformidad prestada por la Junta sea manifiestamente infundada, decidirá el Pleno de la Cámara.

Entrando en el razonamiento que efectúa el Tribunal, la cuestión a dilucidar es «si la atribución al Pleno de la Asamblea de la facultad de rechazar por notoriamente infundada la oposición del Gobierno a la tramitación de una enmienda o de una proposición de ley que alteren las previsiones presupuestarias en relación con los créditos y los ingresos es o no contraria al art. $60 \mathrm{~b}$ ) EAE» (FJ4). ${ }^{18}$

Comienza el Tribunal reconociendo el doble papel de los presupuestos. Son, por un lado, vehículo de dirección y orientación de la política económica que corresponde al Gobierno y, por otro, expresión cualificada de la confianza parlamentaria sobre la que necesariamente ha de construirse cualquier Gobierno. Según el Constitucional, «la ejecución de un presupuesto en curso supone la verificación de dos confianzas: de un lado la obtenida por el Gobierno con la investidura de su Presidente; de otro la concedida específicamente por la Cámara a su programa anual de política económica» (FJ5). Es decir, entiende el Tribunal que el fundamento de la facultad de veto está en esta doble confianza que el Gobierno obtiene del Parlamento en el caso específico de la Ley de Presupuestos.

Después de establecer la tesis de la doble confianza como fundamento del veto presupuestario, el Tribunal se pregunta a quién le corresponde decidir cuándo una proposición de ley tiene repercusiones presupuestarias. Aquí alude al parlamentarismo racionalizado como única justificación de la competencia exclusiva de la Junta en este asunto ${ }^{19}$. Es decir, parece que el Tribunal sabe la respuesta de antemano porque todo su argumentario gira en torno a la defensa de la facultad exclusiva del Gobierno para oponerse, «con toda libertad» a las iniciativas que puedan eventualmente modificar los presupuestos, sin que los órganos parlamentarios puedan emitir un juicio sobre el carácter manifiestamente infundado de la disconformidad. Entiende por tanto que las normas impugnadas alteran el sistema de relaciones entre la Junta y la Asam-

18 La norma contenida en el art. 61 b) del EAE pasa al art. 60 b) tras la reforma del EAE efectuada por la Ley Orgánica 12/1999, de 6 de mayo, de reforma de la Ley Orgánica 1/1983, de 25 de febrero, de Estatuto de Autonomía de Extremadura.

19 Así lo entiende también, entre otros, Aragón Reyes, M.: «este veto gubernamental configura una característica muy relevante del parlamentarismo «racionalizado», mediante el cual se garantiza que, una vez aprobado el Presupuesto por la Cámara, la dirección y ejecución del mismo queda en manos del Gobierno, sin que el Parlamento pueda, sin la aquiescencia del Gobierno, modificarlo o desfigurarlo a lo largo de su vigencia anual». Aragón Reyes, M., (2007). «La organización institucional de las Comunidades Autónomas». Revista española de derecho constitucional, no. 79, p. 24. 
blea previsto estatutariamente porque privan al Ejecutivo de una facultad que debe ejercitar de modo exclusivo y libre. Ejercicio exclusivo y libre porque, mediante el parlamentarismo racionalizado, se «ha pretendido reforzar la posición de los ejecutivos y, singularmente, de sus presidentes, en aras de dotar a todo el sistema de una mayor estabilidad y mejorar su funcionamiento» (FJ6).

Con base en todo lo anterior, el Tribunal estima el recurso de inconstitucionalidad declarando por consiguiente la inconstitucionalidad y, consecuentemente, la nulidad de los apartados segundos de los artículos 111.1 y 121.4 del Reglamento de la Asamblea de Extremadura.

Esta sentencia ha sido duramente criticada por la mayoría de la doctrina. Se señala como error más manifiesto del Tribunal la consideración de la facultad gubernamental como incondicionada, pudiendo el Ejecutivo ejercitarla de modo libre y exclusivo ${ }^{20}$. Es también censurable la falta de argumentación del Constitucional a la hora de declarar como inconstitucional la reforma propuesta: «el Tribunal da por sentado que la reforma impugnada priva al Ejecutivo de una facultad atribuida por el Estatuto de Autonomía» sin apenas desarrollar jurídicamente su posición ${ }^{21}$. O en palabras de Marrero García-Rojo ${ }^{22}$ : «el Tribunal Constitucional considera que la reforma del Reglamento impugnada priva al Gobierno extremeño de la facultad del veto que le atribuye el Estatuto de Autonomía (...). El argumento, o mejor dicho, la conclusión inmotivada, no se sostiene».

Con respecto al fundamento en que el Tribunal asienta la facultad de veto, es interesante la apreciación que realiza Marrero García-Rojo ${ }^{23}$, quien centra su crítica a este respecto en la falta de fundamentación por parte del Tribunal de la doctrina de la doble confianza. Considera que la mera aprobación de la Ley de Presupuestos por parte del Parlamento no conlleva per se un otorgamiento de su confianza a la política económica del Ejecutivo — y por ende al Ejecutivo mismo— pues bien es posible, en su opinión, que, mediante enmiendas, el Parlamento apruebe finalmente una Ley de Presupuestos que difiera del programa económico planteado por el Gobierno inicialmente. Es más, «la aprobación de un presupuesto nada tiene que ver, en estrictos términos técnico-jurídicos, con el otorgamiento por el Parlamento de su confianza al Gobierno». Concluye, por tanto, que la fundamentación del veto ha de ser otra, esto es, se trata de «preservar o de dotar de mayor eficacia al principio de anualidad presupuestaria», constituyendo «el veto presupuestario un instrumento al servicio» de dicho principio, «y a la atribución al Gobierno de funciones de dirección de la política económica, contribuyendo a dotarlos de mayor relevancia o virtualidad».

20 García-Escudero, P. (2006). «Sobre la calificación de las Enmiendas de contenido presupuestario». Repertorio Aranzadi del Tribunal Constitucional, $\mathrm{n}^{\circ} 13$, pp. 53-54.

21 Giménez Sánchez, I. (2017). «El control del Parlamento sobre el llamado «veto presupuestario» del Gobierno». Revista jurídica de Castilla y León, n 42, pp.92-93.

22 Marrero García-Rojo, A. op. cit. p.323.

23 Marrero García-Rojo, A. op. cit. pp. 317-322. 
Entiende el mismo autor que el error principal de la sentencia, y debido al cual el Tribunal concluye afirmando que el Gobierno goza de una facultad de veto presupuestario con carácter exclusivo y libre, estriba en la no distinción de los dos elementos esenciales que configuran el veto.

«El Tribunal confunde aquí dos elementos esenciales del veto presupuestario, (...) esto es, concurrencia del requisito del efecto o repercusión presupuestarios y estricta declaración de voluntad del Gobierno expresando su disconformidad con la tramitación. (...) Determinar si se cumple el requisito del aumento de los créditos o la disminución de los ingresos presupuestarios es una operación técnico-jurídica (...). En modo alguno es una decisión política. En modo alguno es una decisión libre» ${ }^{24}$.

Lo que no podemos saber — sí intuir, por la falta de motivación de la sentenciaes si la relación causal es ésta o más bien la contraria: que partiendo del prejuicio de que el Gobierno goza de dicha facultad incondicionada, el Tribunal «justifique» su posición confundiendo a sabiendas ambos elementos y refugiándose en la doctrina de la doble confianza y en el incuestionable principio del parlamentarismo racionalizado. Esta confusión de elementos se refleja claramente en la especificación que el Tribunal efectúa de la quaestio iuris en el fundamento jurídico sexto, pues «el Tribunal se pregunta a quién le corresponde decidir cuándo una proposición de ley tiene repercusiones presupuestarias». Es decir, está negando de modo implícito la necesidad de que se dé el requisito habilitante de la efectiva repercusión presupuestaria de la proposición de ley o la enmienda. Pero como decíamos antes, sólo cuando exista dicha repercusión presupuestaria el Gobierno está facultado para oponerse a su tramitación ejercitando el veto (esto es, negando su conformidad). No puede el Gobierno decidir si la ley tiene o no repercusiones presupuestarias: ello es un hecho objetivo y objetivable, que precisamente la Reforma del Reglamento trataba de asegurar, evitando con ello un uso arbitrario del veto por parte del Gobierno.

La sentencia entiende que las normas contenidas en la reforma «alteran el sistema de relaciones entre la Junta y la Asamblea previsto estatutariamente» pues «Mesa y Pleno se erigen en jueces de si concurren o no las circunstancias que permiten al Consejo de Gobierno de la Junta de Extremadura oponerse a la tramitación de iniciativas normativas que alteren el equilibrio presupuestario». Sin embargo, tal como señala García Escudero, la mayoría de la doctrina considera que en caso de conflicto la decisión debe mantenerse en el ámbito parlamentario. «Lo mismo ocurre en distintos Reglamentos de Parlamentos autonómicos, que atribuyen la decisión a distintos órganos parlamentarios, desde la Comisión (Aragón), a la Junta de Portavoces (Navarra), la Mesa (Cataluña, Madrid) o el Pleno (Canarias, Asturias, Andalucía, Baleares, Comunidad Valenciana)» ${ }^{25}$.

En opinión contraria a la mayoría de la doctrina, Escribano López reconoce un doble mérito a la presente sentencia. Por un lado, el Tribunal acierta al fijar el ámbito

24 Marrero García-Rojo, A. op. cit., pp. 323-330.

25 García Escudero, P., op.cit. , pp.53-54. 
temporal del art. 134.6 CE: las limitaciones contenidas en dicha norma se refieren sólo al momento de la ejecución del presupuesto, al presupuesto en curso. Por otro, coincide con el Constitucional al considerar la doctrina de la doble confianza como fundamento de la facultad de veto del Gobierno. Dado que el presupuesto ha sido aprobado por la Cámara, «el Gobierno puede pretender legítimamente que las previsiones económicas contenidas en él se observen rigurosamente en el curso de su ejecución del ejercicio presupuestario», puede pretender, en definitiva, que no se desvirtúe «el instrumento económico de su acción de gobierno», tal como recoge el fundamento jurídico quinto ${ }^{26}$.

\subsection{STC 242/06, de 24 de julio.}

La STC 242/06 de 24 de julio, fue pronunciada dieciocho días después de que el Pleno del Tribunal Constitucional dictara la STC 223/06. Tal como señala Marrero García-Rojo, la segunda sentencia no sólo no cita la primera sino que ni siquiera alude a la doctrina sentada por ella para fundar su posición ${ }^{27}$. Este hecho, unido a la aparente contradicción ${ }^{28}$ que presentan las argumentaciones de una y otra sentencia, podría llevarnos a la conclusión de que el Tribunal rectifica de algún modo la doctrina sen-

26 Escribano López, F. (2017). "Los límites gubernamentales al ejercicio de la competencia legislativa por las Cortes: un supuesto de extralimitación del ejercicio de la compe tencia gubernamental". Revista española de derecho financiero, $\mathrm{n}^{\circ}$. 173, pp.17-32.

27 Marrero García-Rojo, A. op. cit., p. 330.

28 Los autores que entienden que ambas sentencias se contradicen son: 1) Marrero García-Rojo, A., quien afirma que «la STC 242/06 se opone frontalmente a la doctrina que acaba de sentar el Pleno Tribunal Constitucional en su STC 223/06» [Marrero García-Rojo, A. en op.ci. p.330]; 2) Giménez Sánchez, I., aunque ésta de un modo menos tajante, pues considera que en la STC 242/06 el Tribunal «se separa en alguna medida del razonamiento ya expuesto en la sentencia anterior» y que «los dos pronunciamientos del Tribunal Constitucional recaídos sobre la cuestión del alcance de la facultad de conformidad del Gobierno a las proposiciones de ley por aumento de crédito o disminución de ingresos resultan contradictorios con respecto a la existencia e intensidad de la capacidad de control del Parlamento respecto del veto opuesto por el Ejecutivo. Así, mientras la STC 223/2006 había defendido el carácter "políticamente libre» del Gobierno en el ejercicio de dicha facultad, en cambio la posterior STC 242/2006 consideraba que la Mesa del Parlamento (en ese caso el vasco) sí tiene margen de decisión y control frente al veto del Gobierno». [Giménez Sánchez, I. (2017). «El control del Parlamento sobre el llamado «veto presupuestario» del Gobierno». Revista jurídica de Castilla y León, n 42, pp. 94 y 95]; 3) Alonso García, M., quien afirma que «estos dos pronunciamientos sucesivos (...) resultan contradictorios, en tanto en cuanto, mientras la STC 223/2006 defiende el carácter «políticamente libre» del Gobierno en el ejercicio de dicha facultad, en cambio la posterior STC 242/2006 considera que la Mesa del Parlamento, en este caso del vasco, sí tenía margen de decisión y control frente al Gobierno vasco. [Alonso García, M. (2018). «Límites del Gobierno en la aplicación del «veto presupuestario»: el art. 134.6 a examen». Diario La Ley, n 9252, p.1]; y, por último, 4) Gómez Corona, E. quien dice que «lo más llamativo de la resolución (...) es que ni siquiera se cite la STC 223/2006, de 6 de julio. Esta omisión sólo puede ser deliberada y responder a la voluntad de apartarse de la doctrina allí fijada pero sin contradecirla expresamente. (...). Esta sentencia obliga a realizar una relectura de la anterior, la STC 223/2006 (...). [Gómez Corona E. (2018). «Las potestades financieras de las Cortes Generales: del uso 
tada en la STC 223/06. Parece que el Tribunal se retracta tímidamente de la declaración sobre la facultad de veto como una facultad exclusiva y libre del Gobierno para reconocer cierto control por parte de la Mesa del Parlamento al ejercicio de la misma.

Si bien es cierto que los argumentos del Tribunal son a primera vista contradictorios, un análisis más profundo y detallado de los mismos nos lleva a la conclusión, - compartida con Sanz Pérez ${ }^{29}$ — de que el Tribunal mantiene, aunque con matices diversos, la misma postura en ambas sentencias.

La oposición entre ellas es más aparente que real y las posibles contradicciones que presentan ambas sentencias se pueden explicar por el hecho de que se trata de procedimientos distintos - recurso de inconstitucional el primero y recurso de amparo el segundo-, lo cual condiciona el objeto del proceso y, consecuentemente, los fundamentos jurídicos.

La STC 242/06 resuelve un recurso de amparo (art. 42 LOTC) interpuesto por varios Diputados del Grupo Parlamentario Popular Vasco, frente a los Acuerdos de la Mesa del Parlamento Vasco que habían inadmitido a trámite (previo ejercicio del veto presupuestario por parte del Gobierno) una proposición de ley presentada por ellos. La proposición planteaba la modificación de un artículo de la regulación sobre régimen presupuestario de la Comunidad Autónoma del País Vasco. La Mesa del Parlamento, que inicialmente había admitido a trámite la proposición de ley, tras recibir el criterio del Gobierno manifestando su disconformidad, la inadmite a trámite mediante dos Acuerdos. «En opinión de los recurrentes, ambos Acuerdos vulneran los arts. 23.2 y 23.1 CE al basarse en una interpretación errónea y sesgada del Reglamento parlamentario que obstaculiza el ejercicio de una función inherente a su cargo representativo y, con él, el derecho de participación ciudadana» (FJ1). Entienden los recurrentes que la disminución de ingresos que el Gobierno aduce como causa de su disconformidad no se produciría sino en un ejercicio futuro, por lo que el Gobierno no estaría facultado para ejercer el veto por ausencia del presupuesto habilitante, de acuerdo con los artículos 103 y 105.2 $2^{30}$ del Reglamento del Parlamento.

al abuso del veto presupuestario sobre las enmiendas con repercusión financiera». Revista general de derecho constitucional, $\mathrm{N}^{\circ} .28$, p. 22 y 23 ].

29 «Puede defenderse, cabalmente, que la intención de la Sala Primera del Tribunal Constitucional en STC 242/2006 ha sido seguir la jurisprudencia sentada apenas dieciocho días antes en STC 223/2006. En su virtud, el Gobierno puede oponerse siempre a la tramitación de una proposición de ley o una enmienda que implique disminución de ingresos presupuestarios» Sanz Pérez, Á.L. (2007). «¿Existe doble confianza en nuestro parlamentarismo? Comentario a la STC 242/2006». Repertorio Aranzadi del Tribunal Constitucional, p.1754.

30 Art. 103: 1. Las enmiendas a un Proyecto de Ley que supongan aumento de los créditos o disminución de los ingresos presupuestarios requerirán la conformidad del Gobierno para su tramitación. No se entenderá que suponen aumento de los créditos las enmiendas que, caso de ser aprobadas definitivamente, difieran su efectividad a un ejercicio presupuestario futuro, ni aquéllas respecto de las que, si superaren el volumen total de créditos presupuestados, el Parlamentario o Grupo proponente indicase en el momento de su presentación con cargo a qué partida del Presupuesto en vigor hubiesen de sufragarse los gastos que ocasione. 2. A tal efecto, la Comisión o la Ponencia encargada de 
Entrando en la fundamentación del Tribunal, no resulta sencillo exponer ordenada y lógicamente sus argumentos, pues si bien en ocasiones son claros y rotundos, renglón seguido se contradice o matiza de tal modo que llega a negar lo anteriormente afirmado.

Empieza considerando el veto como una «potestad del Gobierno, reconocida en el caso del País Vasco en el art. 105.2 de su Reglamento parlamentario» y fija el fundamento de la misma en «la confianza concedida al Gobierno a través de la aprobación del presupuesto para ejecutar su programa anual de política económica sin que éste sea desnaturalizado a través de iniciativas legislativas parlamentarias». En esto no se desvía excesivamente de la STC 223/06, aunque esta última desarrolla el argumento sobradamente. Continúa reconociendo a la Mesa el control de la disconformidad manifestada por el Gobierno: la disconformidad debe hacerse dentro del plazo fijado por la ley (quince días, en este caso), debe ser expresa y debe basarse en el aumento de los créditos o la disminución de los ingresos presupuestarios. Entiende el Tribunal que ello se deduce de la regulación establecida en los arts. 103 y 105.2 del Reglamento del Parlamento. La Mesa goza por tanto de «cierto margen de interpretación sobre cuándo puede considerarse que dicho impacto se produce». Es decir, parece que el Tribunal reconoce a la Mesa del Parlamento cierta función de control sobre el ejercicio del veto por parte del Gobierno, desviándose aparentemente de la doctrina establecida en la STC 223/06, donde entendía el veto como una facultad incondicionada del Gobierno no sometida a control parlamentario de ningún tipo. Por otro lado, dado que la Mesa tiene esta función, el Constitucional fija el «objeto del amparo únicamente en la actuación de la Mesa del Parlamento Vasco» centrando el análisis «en dilucidar si los Acuerdos impugnados han vulnerado los arts. $23.1 \mathrm{y}$ 23.2 CE»(FJ3).

El Tribunal procede inmediatamente a analizar, en los fundamentos jurídicos cuarto y quinto, en qué consiste este deber de control. Se afirma que la Mesa debe examinar, por un lado, los requisitos formales y, por otro $-\mathrm{y}$ si la legalidad aplicable así lo establece-, debe examinar «más allá» de requisitos formales. En cualquier caso, el Tribunal entiende la motivación como un requisito formal, que a su vez posee una

\footnotetext{
redactar el Informe remitirá al Gobierno, por conducto de la Presidencia del Parlamento, aquellas enmiendas que supongan dicho aumento o disminución. 3. El Gobierno deberá dar respuesta razonada en el plazo de quince días, transcurrido el cual se entenderá que su silencio expresa conformidad.

Art. 105. 2: «Ejercitada la iniciativa, la Mesa del Parlamento ordenará la publicación de su presentación y su remisión al Gobierno, para que manifieste su criterio respecto a la toma en consideración de la misma, así como sobre su conformidad o no a su tramitación, si implicara aumento de los créditos o disminución de los ingresos presupuestarios, de acuerdo con lo previsto en el artículo 103 anterior. 3. Transcurridos quince días sin que el Gobierno bubiera expresado su conformidad o reparos a la Proposición presentada, la misma quedará en condiciones de ser incluida en el Orden del Día del Pleno para su toma en consideración. 4. Antes de iniciar el debate, se dará lectura al criterio del Gobierno, si lo bubiere. El debate se ajustará a lo establecido para las enmiendas relativas a la totalidad. 5. Acto seguido, el Presidente preguntará si la Cámara toma o no en consideración la Proposición de Ley de que se trate. En caso afirmativo, la Mesa de la Cámara acordará su inmediata publicación y su remisión a la Comisión competente».
} 
doble dimensión: formal (el mero deber de motivación) y material (la suficiencia de la motivación). A continuación se pronuncia sobre la relación existente entre el ius in officium y la doble naturaleza de las proposiciones de ley (como forma de participación de los parlamentarios en la potestad legislativa y como cauce instrumental al servicio de la función representativa). De dicha relación deriva la obligación de los órganos rectores que inadmiten a trámite las proposiciones de ley de ser «extremadamente rigurosos» con sus decisiones. Dado que la decisión tomada por la Mesa es legal, lo que analiza es si ésta ha sido tomada con una motivación suficiente, es decir, si satisface las exigencias de la motivación formal. El Tribunal entiende que no. Considera que los Acuerdos de la Mesa no recogen las precisas y concretas razones en las que ésta funda su decisión, por lo que «no satisface las exigencias de motivación formal». Pero «este déficit de motivación tampoco debe conducirnos en el presente caso a estimar el presente amparo, dado que lo importante de la dimensión formal del deber de motivación es hacer posible el control de la decisión recurrida». Es decir, el Tribunal fija en el término «control» el punto central a analizar a continuación.

El fundamento jurídico sexto es el que revela de modo claro qué idea maneja el Tribunal sobre el veto, que le lleva a denegar el amparo y a rectificar, en cierta manera, las declaraciones hechas anteriormente. Si se contradice es, justamente, porque el Tribunal sigue considerando el veto presupuestario como una facultad incondicionada, exclusiva y libre del Gobierno, no sometida a ningún tipo de control por parte de la Mesa del Parlamento, tal como manifestó en la STC 223/06. En realidad el control que el Tribunal reconoce a la Mesa no es más que el control genérico que la Mesa del Parlamento debe realizar en todo caso para cumplir su función de órgano rector del Parlamento. Y si el Tribunal lo admite en esta sede es porque el objeto del recurso de amparo le obliga en todo caso a analizar en qué consiste dicho control. Pero cuando dicho control genérico se aplica al caso del veto, el Tribunal lo niega.

Sólo así se entiende el razonamiento del fundamento jurídico sexto y la denegación del amparo. Sentencia el Tribunal que «aunque la propia normativa aplicable limita la conformidad del Gobierno a la concurrencia de un requisito material como la disminución de los ingresos o el aumento de los créditos presupuestarios que, de acuerdo con nuestra doctrina, abre las puertas a un control desde la perspectiva de la proporcionalidad y la razonabilidad, en este contexto es evidente que tanto la Mesa del Parlamento como este Tribunal deben limitarse a un control de una menor intensidad (...) [esto eso]: la Mesa del Parlamento no debe obstaculizar el ejercicio de esta facultad». «Es posible un pronunciamiento de la Mesa sobre el carácter manifiestamente infundado del criterio del Gobierno», es decir, la Mesa debe limitar su control «a las decisiones arbitrarias o manifiestamente irrazonables». Pero, según entiende el Tribunal, no estamos ante este caso porque «no puede afirmarse que la motivación del Gobierno Vasco para fundamentar su disconformidad carezca de verosimilitud y de lógica [pues] el criterio del Gobierno no puede considerarse arbitrario e irrazonable». ¿Por qué? El Tribunal no lo explica, y no lo explica porque, según él, es evidente. Parece tener claro que la facultad del Gobierno es incondicional, exclusiva y libre. 
Parece partir de la convicción de que el Gobierno puede negarse a la tramitación de una ley, incluso en el presente caso en el que no se cumple el requisito que la ley establece de que la disminución de ingresos debe afectar al presupuesto en vigor ${ }^{31}$. Entendemos que si, por un lado, el art. 103 del Reglamento dispone expresamente que no se entiende que hay afectación presupuestaria en el caso de que las enmiendas propuestas se refieran a ejercicios futuros, y por otro, la proposición de ley en el presente caso no afecta al presupuesto en vigor, y aun así, el Gobierno puede libremente negarse a la tramitación de la proposición de ley, es porque la facultad de veto que ostenta el Gobierno es incondicionada; no existe, según el Tribunal, la necesidad de que se dé el presupuesto habilitante para que el Gobierno ejercite el veto.

Esto es lo que puede leerse entre líneas cuando el Constitucional afirma que «lo que en el fondo discuten los recurrentes y el Ministerio Fiscal es el ámbito temporal en que debe producirse dicha disminución de ingresos, que ambas partes sitúan en el mismo ejercicio en que presentó la proposición de Ley objeto de discusión. Pero el criterio del Gobierno, compartido implícitamente por la Mesa del Parlamento, en sentido contrario no puede considerarse arbitrario o irrazonable». ¿Qué argumenta el Tribunal para sustentar su posición? Que la exigencia de afectación al presupuesto en curso no se deduce de los arts. 103 y 105.2 del Reglamento sino que es en realidad una interpretación de los mismos. Y como el art. 23.2 CE no contempla el derecho fundamental a una determinada interpretación de la normativa parlamentaria, la disconformidad del Gobierno es perfectamente razonable y verosímil. Dado lo cual, «una eventual obstaculización de la disconformidad manifestada por el Gobierno hubiese excedido las funciones reservadas al órgano rector del Parlamento Vasco».

Del razonamiento del Tribunal se puede extraer la conclusión expuesta anteriormente de que en realidad ambas sentencias son «hijas de la misma filosofía» ${ }^{32}$, pues ambas conciben el veto como una facultad exclusiva y libre del Gobierno. Esto es, no es necesario que la proposición de ley o la enmienda afecte real y efectivamente al presupuesto en curso para que el Gobierno pueda ejercitar el veto. Por ello no es necesario un control por parte de la Mesa sobre si la decisión del Gobierno es arbitraria o manifiestamente irrazonable, porque evidentemente el Gobierno decide en todo caso si tal afectación se produce. Para este autor, sin embargo, la STC 242/06 va más allá en su «interpretación extensiva pro Gobierno», porque si bien en el caso extremeño la facultad de veto está contemplada en el EAE, en el caso vasco es tan sólo una norma de rango reglamentario la que limita la iniciativa parlamentaria, lo cual hace que la decisión del Tribunal sea todavía más reprochable. Entiende Sanz Pérez que tan sólo

31 Si tenemos en cuenta los argumentos de los recurrentes, la literalidad de la proposición de ley y la finalidad de la misma, que es precisamente «contrarrestar la prórroga presupuestaria anunciada por el Gobierno Vasco para el año 2001», tal como se recoge en el antecedente de hecho número 3 de la Sentencia, todo parece indicar que la reforma de ley planteada por el Grupo Parlamentario Popular no implicaba afectación al Presupuesto en curso.

32 Sanz Pérez, A.L. (2007), « ¿Existe doble confianza en nuestro parlamentarismo? Comentario a la STC 242/2006». Repertorio Aranzadi del Tribunal Constitucional, p. 1755. 
una norma del bloque de constitucionalidad (bien sea la Constitución bien un Estatuto de Autonomía) posee el valor suficiente como para restringir el ius in officium, valor del que carece en todo caso el Reglamento parlamentario. A esto se añade el hecho de que «el Tribunal Constitucional ha vaciado de contenido el carácter presupuestario que deben tener los ingresos afectados por la iniciativa» ${ }^{33}$.

En esta última consideración coincide Escribano López ${ }^{34}$. Como recogíamos supra, uno de los méritos que dicho autor reconocía a la STC 223/06 era el haber fijado el ámbito temporal del veto presupuestario. El Tribunal entendió correctamente que el Gobierno sólo está facultado para limitar la iniciativa parlamentaria en el caso de que la misma afecte a los presupuestos en curso. La crítica a la STC 242/06 no se hace esperar, pues no sólo en este punto el Tribunal niega lo que acertadamente había sentado en la sentencia anterior, sino que «esa deficiente lectura del TC es aún más reprobable» por cuanto el artículo 103 del RPV especifica que «no se entenderá que suponen aumento de los créditos las enmiendas que, caso de ser aprobadas definitivamente, difieran su efectividad a un ejercicio presupuestario futuro».

\subsection{Consecuencias de esta jurisprudencia constitucional en el ejercicio del veto.}

¿Qué puede desprenderse de la doctrina sentada por nuestro Alto Tribunal en estas dos sentencias? Entendemos que la jurisprudencia del Tribunal Constitucional en el presente caso es deficiente en dos puntos principalmente. Asimismo, y tal como desarrollaremos a continuación, este doble defecto ha podido allanar el camino del uso del veto presupuestario como un instrumento político.

En primer lugar, el Tribunal apoya la dinámica que se viene dando en nuestra historia democrática del reforzamiento de la posición del Ejecutivo ${ }^{35}$. Es decir, se une a esta tendencia política, la comparte y la apoya. Podemos incluso afirmar que, dados los efectos vinculantes de su jurisprudencia a todos los aplicadores del Derecho (art. $164 \mathrm{CE}$, art. 40.1 LOTC y art. 5 LOPJ) ${ }^{36}$, nuestro Tribunal consolida esta tendencia. Pero afirmar a secas que el Tribunal «robustece la posición del Ejecutivo» podría ser demasiado injusto hacia el Tribunal Constitucional, porque este proceso de fortalecimiento de los gobiernos trae su causa en la misma configuración que del Poder Ejecutivo hace nuestra Constitución ${ }^{37}$. Son numerosos los trabajos doctrinales que se

33 Sanz Pérez, A.L., op.cit., p. 1757.

34 Escribano López, F. (2017). «Los límites gubernamentales al ejercicio de la competencia legislativa por las Cortes: un supuesto de extralimitación del ejercicio de la competencia gubernamental». Revista española de derecho financiero, $\mathrm{n}^{\circ}$. 173, pp.17-32.

35 En este sentido, véase Sanz Pérez, A.L., op.cit., pp. 170 y 1757.

36 Carrillo, M. (2018). «El Tribunal Constitucional, un balance de cuarenta años». Revista de derecho político, no101, p.634.

37 Cfr. Gómez Corona, E. (2018). «Las potestades financieras de las Cortes Generales:del uso al abuso del veto presupuestario sobre las enmiendas con repercusión financiera». Revista general de derecho constitucional, $\mathrm{N}^{\circ} .28$, p. 2. 
han ocupado de estudiar la posición del Gobierno en nuestra Carta Magna y que concluyen afirmando que es clara la posición central que ocupa éste en ella y su primacía en el campo de la acción política ${ }^{38}$. Tal como defiende Paniagua nuestro «diseño constitucional [que] potencia la posición del Gobierno, para que gobierne; y [que] limita o circunscribe la posición del Parlamento como institución en la que ha de apoyarse el Gobierno para sacar adelante las leyes y dirigir la política nacional. Un Gobierno estable y un Parlamento «frenado»» ${ }^{39}$. El propio Tribunal así lo reconoce, pues no duda en declarar que mediante el parlamentarismo racionalizado, se «ha pretendido reforzar la posición de los ejecutivos y, singularmente, de sus presidentes, en aras de dotar a todo el sistema de una mayor estabilidad y mejorar su funcionamiento» (FJ6 de la STC 223/06).

Pensamos por tanto que, en este punto, nuestro Tribunal ha cumplido más bien un papel coadyuvante, pues la jurisprudencia emanada de estas sentencias ha propiciado en cierta medida que los Ejecutivos se vieran todavía más respaldados en sus posiciones preeminentes frente al Parlamento, al menos en lo que se refiere al ejercicio del veto presupuestario.

En segundo lugar, el Tribunal no lleva a cabo una adecuada labor interpretativa del art 134.6 CE. No clarifica de modo definitivo los contornos de la potestad de veto presupuestario, ni resuelve las cuestiones controvertidas que en torno a esta figura se plantean. En este sentido, algunos autores afirman que la interpretación que hace el Tribunal del art. 134.6 CE es extensiva ${ }^{40}$. Con afirmaciones abstractas del tipo «la Mesa del Parlamento no debe obstaculizar el ejercicio de esta facultad» o «es posible un pronunciamiento de la Mesa sobre el carácter manifiestamente infundado del criterio del Gobierno», o bien, la Mesa debe limitar su control «a las decisiones arbitrarias o manifiestamente irrazonables», es bastante difícil hacerse cargo sobre qué tipo de control en concreto debe realizar la Mesa. ¿Qué quiere decir exactamente «carácter manifiestamente infundado»? (FJ6 STC 242/06). Ciertamente se trata de un concepto jurídico indeterminado, y como tal, difícil de concretar, pues como lo define el Diccionario del Español Jurídico, se trata de un «concepto utilizado por las normas del que no puede deducirse con absoluta seguridad lo que aquellas han pre-

38 Cfr. Entre otros: López Guerra, L.M. (1998). «La posición del Gobierno en la Constitución Española». Coord. por Álvarez Conde, E. Administraciones públicas y Constitución: reflexiones sobre el XX aniversario de la Constitución española de 1978, Madrid, Instituto Nacional de Administración Público, pp. 353-366 y el mismo autor (1988). «La posición constitucional del Gobierno». Gobierno y administración en la Constitución, Madrid, Ministerio de Hacienda, Institutos de Estudios Fiscales, Vol. 1, pp.16-33; y Otto Pardo, I. (1980). «La posición constitucional del Gobierno». Documentación Administrativa. pp.139-180.

39 Paniagua, J.L. (2012). «España: un parlamentarismo racionalizado de Corte Presidencial». Presidencialismo y parlamentarismo: América Latina y América Latina y Europa Meridional: Argentina, Brasil, Chile, España, Italia, México, Portugal y Uruguay, Jorge Lanzaro (ed. lit.), p. 227.

40 cfr. Alonso García, M.N. (2018). «Límites del Gobierno en la aplicación del «veto presupuestario»: el art. 134.6 a examen». Diario La Ley, no 9252, p.3 y Sanz Pérez, A.L., op.cit, p. 1755. 
tendido exactamente, siendo difícil alcanzar una solución exacta» ${ }^{41}$. En este punto pues, el Alto Intérprete simplemente afirma que la Mesa debe limitar el control a las «decisiones arbitrarias o manifiestamente irrazonables», sin especificar qué habría que entender como decisión arbitraria o irrazonable en el concreto ejercicio de la facultad de veto por parte del Gobierno.

Asimismo, cuando el Tribunal se pregunta a quién le corresponde decidir cuándo una proposición de ley tiene repercusiones presupuestarias (FJ6 STC 223/06) y concluye que es al Gobierno, está haciendo una interpretación un tanto extraña del adjetivo «presupuestario» que aparece en el letra del art. 134.6 CE al hablar de los ingresos y gastos que deben verse afectados por la iniciativa legislativa en cuestión. Al contrario del Tribunal, entendemos, como desde el inicio ha hecho la doctrina, que si la literalidad de la norma habla de ingresos y gastos presupuestarios, estos han de tener un efectivo reflejo en la Ley de Presupuestos, sin que el Gobierno tenga ningún margen de decisión en este hecho objetivo. Es decir, la jurisprudencia no esclarece ni de lejos el alcance objetivo de esta norma. Habrá que esperar a la STC $34 / 18$ para aclarar estos y otros aspectos.

La única aclaración que realiza en la STC 223/06 es la delimitación del ámbito temporal de la facultad del veto (que la iniciativa afecte el ejercicio presupuestario en curso), pero, desgraciadamente, se desmiente en la STC 242/06, dejando también sin precisar el alcance temporal del veto. En definitiva, el Tribunal en su defectuosa labor interpretativa, llega a vaciar de contenido el carácter presupuestario que deben tener los ingresos y gastos afectados por las iniciativas sujetas a la conformidad del Gobierno ${ }^{42}$.

Estamos de acuerdo con Sanz Pérez cuando afirma que «hasta que no se cambie el rumbo de la jurisprudencia, cualquier oposición del Gobierno puede ser suficiente para que no se debata una iniciativa» ${ }^{43}$. Como expondremos a continuación y tal y como anunciaba este autor en 2007 , se han desarrollado los acontecimientos políticos en este asunto del veto presupuestario en la XII legislatura.

No pretendemos culpar al Constitucional del uso abusivo del veto. En el suceder de los acontecimientos políticos el protagonista no ha sido el Tribunal Constitucional sino el Gobierno. Quien ha llevado a cabo una aplicación del art. 134.6 que desborda las previsiones constitucionales ha sido el Ejecutivo ${ }^{44}$. Pero cabe preguntarse si, en el caso de que el Tribunal hubiera llevado a cabo una correcta interpretación del precepto constitucional, los acontecimientos hubieran acaecido de modo diverso. Quizá si hubiera resuelto con la calidad jurídica que debiera esperarse de un Tribunal Constitucional, los Gobiernos habrían tenido más difícil el uso del veto como un instrumento político. Una hermenéutica auténtica deja sin duda menos margen para una interpretación viciada en provecho de alguna de las partes.

41 Diccionario del Español Jurídico, (2016). Dirigido por Santiago Muñoz Machado, Real Academia Española, Consejo General del Poder Judicial, Barcelona, Ed. Espasa, p. 436.

42 Sanz Pérez, A.L., op.cit., p.1757.

43 Sanz Pérez, A.L., op.cit., p.1757.

44 Cfr. Delgado Ramos, D., op.cit., p. 78. 
Pero como decimos los hechos se hallan en el campo de lo político, por lo que las causas que han de buscarse son de índole política. En realidad, hasta la XII legislatura «la aplicación de esta prerrogativa ha sido poco frecuente en la práctica parlamentaria, fundamentalmente por la existencia de mayorías parlamentarias, pero comienza a adquirir protagonismo en los últimos años por la tendencia a la formación de gobiernos en minoría» ${ }^{45}$.

Tan sólo interesa señalar por tanto los datos del uso del veto en la XII legislatura, puesto que es en este momento histórico donde se produce un cambio político radical y donde, como consecuencia de dicha alteración en la composición de las Cámaras, el Gobierno «se ve obligado» a acudir a cualquier herramienta política que le permita mantener la posición de preeminencia que hasta ahora tenía — pues se hallaba apoyado por sólidas mayorías parlamentarias_- y quizá haya perdido de modo irreversible. Es aquí donde el Gobierno de Mariano Rajoy llega a abusar del ejercicio del veto como medio para mantener su programa político. Puesto que no cuenta con el apoyo suficiente de las Cámaras ${ }^{46}$ para que sus iniciativas legislativas sean aprobadas, ni por tanto para que las de la oposición sean frenadas, el Gobierno recurre a la disconformidad por razones presupuestarias ${ }^{47}$ —es decir, al veto presupuestario — para frenar todas aquellas proposiciones de ley que no le interesan políticamente ${ }^{48}$. Que tales iniciativas legislativas conlleven o no alteraciones presupuestarias es del todo irrelevante, puesto que, tal como afirmaba el Constitucional en el lejano 2006, el Gobierno decide cuándo una proposición tiene repercusiones presupuestarias. Así las cosas el Ejecutivo ha llegado a negar su conformidad a la tramitación de cincuenta y tres proporciones de ley de grupos parlamentarios de la oposición, todas ellas entre diciembre de 2016 y abril de $2018^{49}$. Es decir, en apenas año y medio, coincidiendo

45 Alonso García, M.N., op.cit., p. 3.

46 La composición de la Cámara del Congreso de los Diputados en la XII legislatura fue la siguiente: Grupo Popular: 137; Grupo Socialista: 84; Confederal de Unidos Podemos-En Comú Podem-En Marea: 67; Ciudadanos: 32; ERC: 9; PNV (EAJ-PNV): 5; Grupo Mixto: 19

47 Así lo afirma claramente Gómez Corona, E. cuando dice que «la peculiar composición del Congreso de los Diputados en esta legislatura, sin mayorías claras, llevó al Gobierno de Mariano Rajoy a usar y abusar de su facultad de veto, llegando a oponerse a iniciativas en las que podía cuestionarse la repercusión presupuestaria o que no afectaban al presupuesto en vigor sino a los siguientes, quedando por tanto al margen del ámbito de aplicación del artículo 134.6 CE». Gómez Corona, E. (2018), op.cit, p. 16.

48 En este sentido opina Escribano López cuando dice que el uso del veto «pueda ser la tónica general, la estrategia, en suma, mediante la que el Gobierno pretenda que a la mayoría del Parlamento, que no le apoya, se le impida adoptar medidas de alcance legislativo en contra de los intereses del Gobierno: por ejemplo, de hecho, en el mantenimiento de toda su política legislativa anterior». Escribano López, F. (2017). «Los límites gubernamentales al ejercicio de la competencia legislativa por las Cortes: un supuesto de extralimitación del ejercicio de la competencia gubernamental». Revista española de derecho financiero, $\mathrm{n}^{\circ} .173, \mathrm{p} .17$.

49 Desglose de datos del ejercicio del veto por años durante este periodo. El Gobierno de Mariano Rajoy ejercitó el veto en cada de los periodos las siguientes veces:

-Entre septiembre y diciembre de 2016: 13 veces (una vez en septiembre, y 12 en diciembre). 
el comienzo del ejercicio del veto con el inicio de la segunda investidura del Presidente, y terminando en el momento en el Tribunal Constitucional dicta las famosas SSTC 34/2018 de 12 de abril y 44/2018 de 26 de abril, que supondrán un viraje definitivo tanto en la jurisprudencia constitucional como - y pensamos a consecuencia de ella-, en el uso del veto como un instrumento político.

Como se ha visto, la doctrina denunció desde el principio esta utilización abusiva del veto presupuestario por parte del Gobierno. Asimismo, señaló acertadamente que el problema de fondo se hallaba en una aplicación del artículo 134.6 CE que desbordaba las previsiones constitucionales ${ }^{50}$. Pero para poder aplicar dicho artículo dentro de los márgenes constitucionales es menester llevar a cabo una correcta interpretación del mismo, labor llevada a cabo por nuestro Alto Tribunal.

\subsection{Giro jurisprudencial de la STC 34/2018, de 12 de abril.}

Una vez expuestos los límites y las consecuencias de la jurisprudencia constitucional contenida en las SSTC 223/06 y 242/06, analizaremos pormenorizadamente la doctrina que dimana de la STC 34/2018 de 12 de abril, pues ella encierra toda la novedad interpretativa que, en torno al veto presupuestario, ha emanado de nuestro Alto Intérprete hasta la fecha. No se puede decir que dicha doctrina sea exhaustiva, pero sí bastante como para clarificar el precepto de modo suficiente en orden a poner fin a su uso inicuo por parte del Ejecutivo.

Porque tal como reconoce el propio Tribunal en la STC 34/18, «lo cierto es que la doctrina sentada en las dos Sentencias citadas [STC 223/06 y STC 242/06] resulta por sí misma insuficiente» (FJ5). Asimismo, «hasta las SSTC 34/18 y 44/18, los

-Durante todo el año 2017: 26 veces.

-Entre enero y abril de 2018: 13 veces.

Si comparamos con los datos del ejercicio del veto presupuestario en cada una de las legislaturas:

I Legislatura (1979-1982): 0

II Legislatura (1982-1986): 7

III Legislatura (1986-1989): 16

IV Legislatura (1989-1993): 0

V Legislatura (1993-1996): 0

VI Legislatura (1996-2000): 0

VII Legislatura (2000-2004): 0

VIII Legislatura (2004-2008): 22

IX Legislatura (2008-2011): 0

X Legislatura (2011-2016): 0

XI Legislatura (2016-2016): 0 Sánchez)

XII Legislatura (2016-2019): 54 (53 veces el Gobierno de Mariano Rajoy, una vez el de Pedro

Fuentes: Memorias de cada una de las legislaturas y buscador de iniciativas de la página web del Congreso de los Diputados: http://www.congreso.es/portal/page/portal/Congreso/Congreso/Iniciativas

50 Delgado Ramos, D. (2018) «El veto presupuestario del Gobierno», Problemas actuales de Derecho Parlamentario, Aranzadi, pp. 114 y 133. 
contornos del art. 134.6 CE eran imprecisos» ${ }^{51}$. Tal y como demostramos supra, qué duda cabe que dicha insuficiencia e imprecisión propiciaron el suceder de los acontecimientos políticos tal y como los conocemos. Era necesidad acuciante determinar con claridad el alcance de la norma contenida en el art. 134.6 CE, a fin de evitar, o al menos reducir, el uso de la facultad del veto gubernamental como un instrumento político. Y la interpretación adecuada de tal precepto la podemos encontrar en la STC $34 / 2018$, donde en su fundamento jurídico séptimo contiene una interpretación correcta del veto presupuestario ${ }^{52}$. Sin lugar a dudas, esta sentencia va a suponer un giro copernicano en la interpretación del art. 134.6 CE. Como sostenemos, el cambio de la doctrina jurisprudencial en torno al veto presupuestario que se opera a partir de ella, suponen el inicio del fin del uso abusivo del veto presupuestario por parte del Gobierno $^{53}$. La labor efectuada aquí por el Tribunal nos confirma la idea que recoge Díaz Revorio de que «uno de los retos fundamentales del intérprete constitucional es dar una respuesta jurídica a un problema político» ${ }^{54}$, porque el carácter político de un acto no impide el conocimiento jurídico del mismo ${ }^{55}$.

\subsubsection{Breve panorámica de la jurisprudencia reciente en torno al veto.}

Tal y como decimos, pensamos que la sentencia del todo relevante es la STC $34 / 2018$, dado lo cual, centraremos nuestro análisis en el contenido de la misma, haciendo referencia al resto de sentencias de nuestro Constitucional en lo que sea pertinente. Conviene sin embargo tener una visión panorámica y cronológica de las mismas, pues aunque las otras cuatro sentencias sobre el tema dictadas por nuestro Tribunal Constitucional en el año 2018, así como la última, de 2019, se limitan a recoger la doctrina de la STC 34/2018 y a aplicarla a los casos que enjuician, no dejan de ser todas ellas relevantes en cuanto a la doctrina constitucional sobre el art. 134.6 CE se refiere. En total, cinco sentencias, de las cuales, las dos primeras (las SSTC $34 / 2018$ y 44/2018) resuelven dos conflictos de atribuciones, y las otras tres (las SSTC 94/2018, 139/2018 y la 17/2019), ventilan tres recursos de amparo.

51 Ruiz Almendral, V. (2018). «El presupuesto del Estado: una (re)visión constitucional». Revista española de Derecho Financiero, n ${ }^{\circ} 179$, p. 146.

52 Ruiz Almendral, V., op.cit., p. 147.

53 La última vez que el Gobierno de Mariano Rajoy negó la conformidad a la tramitación de una iniciativa legislativa fue 20 de abril de 2018, ocho días después de que el Tribunal Constitucional dictara la STC 34/18. Se trataba de la «Proposición de Ley para adaptar la Ley 49/1960, de 21 de julio, de Propiedad Horizontal a la Convención sobre los derechos de las personas con discapacidad de la ONU», presentada por el Grupo Parlamentario Socialista. Desde ese momento hasta la actualidad, tan sólo una vez más el Gobierno de Pedro Sánchez ha ejercitado el veto presupuestario, esta vez el 14 de septiembre de 2018, ante la «Proposición de Ley de mejora de la autonomía y la rendición de cuentas de las universidades españolas», presentada por el Grupo Parlamentario Ciudadanos.

54 Díaz Revorio, F.J. (2016). «Interpretación de la Constitución y juez constitucional». Revista del Instituto de Ciencias Jurídicas de Puebla, $\mathrm{n}^{\circ} 37$, p. 15.

55 Bachof, O. (1989). Jueces y Constitución, Madrid, Civitas, p. 61. 
Como decimos, las SSTC 34/2018 de 12 de abril y 44/2018 de 26 de abril resuelven dos conflictos entre órganos constitucionales —o conflictos de atribucionespromovidos por el Gobierno contra el Congreso de los Diputados. En ambos procesos el Ejecutivo considera que los Acuerdos de la Mesa han producido un menoscabo de la competencia derivada del art. 134.6 CE.

Tal y como establece el art. 73 LOTC, el Tribunal Constitucional conoce del conflicto entre órganos constitucionales del Estado «en el caso en que alguno de los órganos constitucionales a los que se refiere el artículo 59.3 de esta Ley, por acuerdo de sus respectivos Plenos, estime que otro de dichos órganos adopta decisiones asumiendo atribuciones que la Constitución o las Leyes orgánicas confieren al primero». El propio Tribunal a través de su jurisprudencia ha ido clarificando qué tipo de actos o decisiones de un órgano constitucional pueden ser objeto de un conflicto de atribuciones (SSTC 45/1986, de 17 de abril, y 234/2000 de 3 de octubre). Si bien en un primer momento sólo fueron reconocidos como tales aquellos que implicaran una invasión de atribuciones — tal y como recoge el art. 75.2 LOTC $^{56}$ — , en un segundo momento el Tribunal considera que una lesión por menoscabo de las facultades conferidas a un órgano constitucional por parte de otro puede ser objeto de impugnación ante el Tribunal Constitucional. Así es recogido en los fundamentos jurídicos tercero y segundo de la STC 34/18 y $44 / 18$, respectivamente, donde se afirma que los Acuerdos de la Mesa impugnados por el Gobierno en ambos procesos se acomodan al objeto del conflicto entre órganos constitucionales.

Por su parte, las SSTC 94/18, 139/18 y 17/19 resuelven tres recursos de amparo (art. 42 LOTC), dictados por la Sala Segunda, por la Sala Primera y por la Sala Segunda del Tribunal Constitucional, respectivamente. En los tres casos, son Grupos Parlamentarios quienes alegan vulneración del art. 23 CE por parte de la Mesa del Congreso por aceptar el criterio de disconformidad del Gobierno, impidiendo la tramitación de sendas proposiciones de ley. Estas tres sentencias no suponen un avance en el doctrina sentada por el Tribunal, pues el Constitucional se limita a resumir la jurisprudencia anterior en los dos aspectos que analiza: la facultad de veto, por un lado, y el derecho fundamental de los parlamentarios a la participación política, y por ende, sobre el derecho de los ciudadanos a participar en los asuntos públicos a través de sus representantes legítimos, por otro. Resume lo dicho y lo aplica al presente caso, concluyendo que, en los tres procesos, la Mesa vulnera el ius in officium de los parlamentarios con su actuación. En este sentido, los tres juicios manifiestan claramente la innegable limitación a la iniciativa legislativa parlamentaria que conlleva el ejercicio de la facultad de veto presupuestario. De ahí que el Tribunal recoja en los tres procesos (en los FFJJ 4, 4 y 2 de las SSTC 94/18, 139/18 y 17/19, respectivamente) la doctrina constitucional sobre la interpretación restrictiva que debe hacerse «de

56 Art. 75.2 LOTC: «La sentencia del Tribunal determinará a qué órgano corresponden las atribuciones constitucionales controvertidas y declarará nulos los actos ejecutados por invasión de atribuciones y resolverá, en su caso, lo que procediere sobre las situaciones jurídicas producidas al amparo de los mismos». 
todas aquellas normas que puedan suponer una limitación al ejercicio de aquellos derechos o atribuciones que integran el estatuto constitucionalmente relevante del representante público y a motivar las razones de su aplicación, bajo pena, no sólo de vulnerar el derecho fundamental del representante de los ciudadanos a ejercer su cargo (art. 23.2 CE), sino también de infringir el de estos a participar en los asuntos públicos ex artículo 23.1 CE (SSTC 38/1999, FJ 2; 107/2001, FJ 3; 40/2003, FJ 2; 1/2015, FJ 3; 23/2015, de 16 de febrero, FJ 3, y 10/2018, de 5 de febrero, FJ 3)».

\subsubsection{STC 34/2018, de 12 de abril.}

Procedamos pues a analizar detalladamente la primera de las sentencias, la STC 34/2018 de 12 de abril, en la cual el Gobierno impugna el Acuerdo de la Mesa del Congreso de los Diputados con fecha 18 de octubre de 2016. Mediante dicho Acuerdo, la Mesa rechaza la disconformidad del Gobierno a la tramitación por el Pleno de la proposición de ley orgánica presentada por el Grupo Parlamentario Socialista sobre la suspensión del calendario de la implantación de la Ley Orgánica 8/2013, de 9 de diciembre, para la mejora de la calidad educativa (LOMCE). La disconformidad del Gobierno para su tramitación se fundamenta en un informe del Ministerio de Educación, Cultura y Deporte donde se intenta justificar la disminución de ingresos presupuestarios que la proposición de ley podría suponer. La Mesa del Congreso, por su parte, considera que el criterio del «Gobierno no justifica de forma objetiva y suficiente que la proposición de ley implique aumento de créditos o disminución de ingresos del Presupuesto en vigor».

Con respecto a las alegaciones de las partes, interesa tan sólo apuntar, por un lado, con base en qué argumenta el Gobierno que la proposición de ley afecta a los presupuestos y, en su contra, porqué la Mesa defiende que tal afectación no se produce.

La Abogacía del Estado considera que es evidente que la proposición de ley afecta a los Presupuestos en vigor (los de 2016), pues la paralización de la LOMCE implica una disminución de ingresos presupuestarios que cuantifican para el año 2016, entre 211,4 y 234,8 millones de euros, y para el año 2017 entre 257,4 y 261,9 millones de euros. Tales ingresos los espera recibir el Ministerio de Educación, Cultura y Deporte del Fondo Social Europeo (FSE) en virtud del Programa Operativo Empleo, Formación y Educación 2014-2020. El Ministerio asumió el compromiso de financiar una parte de la inversión derivada de la implantación de la LOMCE, y de anticipar los fondos necesarios para realizar la parte de dicha inversión susceptible de ser financiada con cargo al FSE.

Por su parte, la Letrada de las Cortes, además de refutar cada una de las argumentaciones del recurrente, alega que el Gobierno no ha identificado la partida presupuestaria que demuestre que la financiación de la LOMCE con cargo al Fondo Social Europeo (FSE) es un ingreso presupuestario del Estado español. Además, considera que la disminución de ingresos alegada por el Gobierno es eventual y futura, condi- 
cionada a la decisión del FSE, por lo que la pérdida de ingresos sería hipotética. Con base en ello, el Gobierno no estaría en condiciones de ejercitar el veto, pues la disminución de ingresos debe ser real y encontrarse en la propia Ley de Presupuestos.

Tras afirmar que la controversia se acomoda al objeto del conflicto entre órganos constitucionales, el Tribunal Constitucional centra el tema, y fija el objeto del proceso en determinar si el acuerdo de la Mesa tiene un contenido hipotéticamente invasor, al frustrar el ejercicio de una atribución que el Gobierno considera como propia. Para ello procede a examinar el art. 134.6 CE. La potestad constitucional contenida en dicho artículo se reproduce para las enmiendas a un proyecto de ley, y para las proposiciones de ley, respectivamente, en los arts. 111 y 126 del Reglamento del Congreso de los Diputados. Puesto que de la literalidad de ambos preceptos (constitucional y reglamentario) no puede deducirse ninguna regla adicional en relación al procedimiento a seguir, el Constitucional se dispone a analizar el contenido de las SSTC 223/06 y 242/06, concluyendo que la doctrina sentada por ambas sentencias es insuficiente para resolver el presente conflicto. Por ello, «resulta necesario concretar con mayor precisión los contornos de la potestad del art. 134.6 CE».

Consideramos que es del todo acertado el método seguido por el Tribunal para poder determinar la interpretación adecuada de este precepto constitucional. Para ello, el Tribunal sigue el siguiente íter. Partiendo de consideraciones generales, concluye en lo particular del caso; siguiendo una lógica deductiva, podemos decir que va al núcleo del asunto. En un primer momento examina detenidamente el 134. Seguidamente, estudia la potestad de veto contenida en su apartado sexto y, por último, y con base en lo anterior, analiza si en el presente caso el menoscabo alegado por el Gobierno se ha producido.

\section{A) Doctrina sobre el reparto de competencias como resultado de la singu- laridad de la Ley de Presupuestos.}

Así pues, en el fundamento jurídico sexto el Tribunal enmarca el tema. Para poder comprender el veto presupuestario de un modo adecuado, es menester contextualizarlo convenientemente, esto es, tener presente que la facultad de veto la encontramos en el apartado sexto del artículo 134 CE. Por tanto, hemos de partir de la doctrina sobre el reparto de competencias presupuestarias que entre el Ejecutivo y el Legislativo se refleja en el art. $134 \mathrm{CE}$. Como dice el Constitucional, lo determinante para entender el régimen jurídico del veto presupuestario «es la propia función instrumental que el Presupuesto cumple al servicio de la acción del Gobierno». El Tribunal entiende adecuadamente que el fundamento del veto está en la naturaleza, contenido y función de la Ley de Presupuestos, que le otorga la condición de ser una norma del 
todo singular y con base en tal singularidad el texto constitucional prevé todo una serie de particularidades recogidas en el art. $134 \mathrm{CE}^{57}$.

El Gobierno, a quien le corresponde la función de dirección y orientación de la política económica, encuentra en el Presupuesto el instrumento principal para llevar a cabo dicha función. De ahí, por un lado, la importancia y el carácter especial de la Ley de Presupuestos, y, de otro, el papel preponderante del Gobierno en el Presupuesto, tal como refleja el mentado artículo. Por tanto, la primera de las singularidades de la ley de presupuestos la encontramos en el reparto de las competencias que en torno a dicha ley establece la Constitución. Al Gobierno le corresponde «la elaboración de los Presupuestos Generales del Estado» (art. 134.1), así como su control y ejecución. Al Parlamento por su parte le compete el examen de Ley de Presupuestos presentada por el Gobierno, la enmienda y la aprobación (art. 134.1), consagrando así el principio de legalidad presupuestaria. Tal como apunta el Tribunal, «es precisamente este citado reparto de poderes lo que hace de la ley de presupuestos una norma singular». Ya en 1968 Rodríguez Bereijo desarrolló ampliamente esta doctrina, comprendiendo el Presupuesto como «la institución de Derecho Público que con mayor claridad expresa el carácter de compromiso entre poderes del régimen parlamentario», pues la distribución de competencias que se opera en materia presupuestaria, permite mantener el equilibrio entre Parlamento y Gobierno ${ }^{58}$. El Tribunal entiende aquí el Presupuesto como «manifestación del ejercicio condomial del poder» entre el Ejecutivo y el Legislativo, es decir, como reflejo de dos competencias, como el corolario del ejercicio de la función de gobernar y de la función de legislar y controlar esa función de Gobierno ${ }^{59}$.

57 En 1995, Rodríguez Bereijo Á., analizando la jurisprudencia constitucional en torno al Derecho Presupuestario, ya recogía esta la doctrina diciendo: «la singularidad o especificidad de la Ley de Presupuestos la hace derivar el Tribunal Constitucional (...) de tres notas singulares, a saber: a) Del carácter instrumental del Presupuesto en relación con la política económica (cualificación de la Ley de Presupuestos como «vehículo de dirección y orientación de la política económica que corresponde al Gobierno»). b) De las normas que regulan el procedimiento parlamentario de debate y aprobación de la Ley de Presupuestos, que limitan la iniciativa legislativa parlamentaria y el derecho de enmienda y restringen, por consiguiente, los derechos y competencias del Parlamento (art. 134.5 y 6 CE; Reglamento del Congreso de los Diputados, arts. 133 a 135, y Reglamento del Senado, arts. 148 a 151, que si bien reconocen la especialidad de la tramitación del proyecto de Ley de Presupuestos lo incluyen de manera inequívoca dentro del procedimiento legislativo y no en otra función parlamentaria distinta). c) Del carácter esencialmente temporal que tiene la Ley de Presupuestos (art. 134.2 CE). Rodríguez Bereijo, Á. (1995). «Jurisprudencia constitucional y Derecho Presupuestario: cuestiones resueltas y temas pendientes». Revista Española de Derecho Constitucional, núm. 44, 1995, pp. 16 y 17.

58 Rodríguez Bereijo, Á. (1968). «La limitación de la iniciativa parlamentaria en materia presupuestaria en el derecho positivo español» Revista de la Facultad de Derecho de la Universidad de Madrid, $\mathrm{N}^{\circ} .33$, p. 439.

59 Escribano López, F. (2018). «Acerca del régimen jurídico constitucional de las proposiciones de ley que impliquen aumento de gasto o disminución de ingresos presupuestados (Un comentario a las SSTC 34/2018 y 44/2018)». Revista española de derecho financiero, n 180, pp. 163 y 188. 
La singularidad de la que hablábamos se refleja, en segundo lugar, en su naturaleza de ley temporal, pues de acuerdo con el art. 134.2 «los Presupuestos Generales del Estado tendrán carácter anual», sin prejuicio de la posibilidad de que sean prorrogados automáticamente los del ejercicio anterior «si la Ley de Presupuestos no se aprobara antes del primer día del ejercicio económico correspondiente» hasta la aprobación de los nuevos (art. 134.4)

La tercera de las particularidades de la ley de presupuestos se halla en la relación de competencia en la que se encuentra con respecto al resto de leyes ordinarias. El Tribunal afirma, con base en dicho principio de competencia, que las leyes que incidan en el Presupuesto deben contar con la conformidad del Gobierno, pues en materia presupuestaria sólo la ley de presupuestos es competente, por lo que se entiende que una vez aprobados los presupuestos, sólo el Gobierno puede incidir en los mismos, ya sea de un modo positivo — presentando proyectos de ley que impliquen aumento del gasto público o disminución de los ingresos (art. 134.5)—, o de un modo negativo — negando su conformidad a las proposiciones de ley o a las enmiendas que supongan un aumento del gasto o una disminución de los ingresos presupuestarios (art. 134.6)—.

En definitiva, el veto presupuestario encuentra su fundamentación en la singularidad de la Ley de Presupuestos ${ }^{60}$, que a su vez se explica por la importantísima función que cumple como instrumento para hacer efectiva la política económica del Gobierno.

Si comparamos con la jurisprudencia anterior, constatamos que, en este caso, el Tribunal no parte del principio genérico del parlamentarismo racionalizado sino de la singularidad de la ley de presupuestos. Esto es, en las SSTC 223/06 y 242/06 el Tribunal concede al Gobierno una potestad de veto con carácter exclusivo y libre porque, tal como están configuradas las relaciones entre los poderes legislativo y ejecutivo en nuestro sistema parlamentario, la primacía la tiene el Gobierno. Sin embargo, el enfoque de la STC 34/2018 no es el de la configuración de nuestro parlamentarismo en sentido genérico, sino el de la distribución de competencias que en el concreto ámbito presupuestario dispone la Constitución.

Es cierto que la STC 223/06 en su fundamento jurídico quinto ya recogía esta doctrina constitucional que desarrolla la STC 34/18, pues afirmaba que los presupuestos son el «vehículo de dirección y orientación de la política económica que corresponde al Gobierno», y «en su condición de vehículo de dirección de la política

60 En el artículo citado Escribano López critica la caracterización que el Tribunal hace de los Presupuestos en la STC 34/18 por considerarla «un intento frustrado». Entiende este autor que el Constitucional no «aprovecha la ocasión, al hablar de la prórroga, del esencial carácter de la misma para poner de manifiesto el comentado carácter de ejercicio competencial equilibrado en que consiste su régimen jurídico constitucional: la automaticidad de la misma». En segundo lugar, como ya hemos señalado, considera desafortunada la cita que recoge de la STC 136/2011, y, por último, se le antoja «insuficiente la caracterización del art. 134.6 CE en dos aspectos fundamentales (...), a saber: que ha sido largo y fatigoso el proceso de distinguir los tempi absolutamente diversos entre los dos párrafos 134.5 y 134.6 (...) y que ésta es la tercera sentencia que entra a establecer el interpretación constitucional del contenido y requisitos del mal llamado veto presupuestario». Escribano López, F. (2018), op.cit., p. 189. 
económica del Ejecutivo el presupuesto es un instrumento fundamental para la realización de su programa de gobierno». Sin embargo, pensamos que, tal como desarrollamos supra (§ La STC 223/06, de 6 de julio) en aquella ocasión el Tribunal fundamenta la potestad de veto en la doctrina de la doble confianza. Por el contrario, la STC 34/18 afirma que «aunque el denominado «veto presupuestario» sea un reflejo de la confianza otorgada por la Cámara, que no podrá después, yendo contra sus propios actos, retirar de forma indirecta por la vía de una iniciativa parlamentaria, lo determinante para su régimen jurídico es la propia función instrumental que el Presupuesto cumple al servicio de la acción del Gobierno»

Está claro que, en último término, cuando hablamos de la doctrina del reparto de competencias presupuestarias nos movemos también en el ámbito de las relaciones entre las Cortes Generales y el Gobierno. Pues tal como entiende Escribano López, «los problemas que se suscitan en la aplicación de las reglas al hilo del art. $134 \mathrm{CE}$ son, a la vez, lógicamente, de inmediato interés presupuestario, mas, al tiempo, de ahí su extraordinaria relevancia, se originan, nacen, se ponen en cuestión, en momentos de crisis, más o menos intensas, en el nunca fácil equilibrio constitucional en el ejercicio de sus respectivas competencias entre el Gobierno y las Cámaras representativas» ${ }^{61}$. Sin embargo, parece que en las SSTC 223/06 y 242/06 el Constitucional responde a la pregunta de cuál es nuestro sistema parlamentario, concluyendo que, dado que el nuestro es un parlamentarismo racionalizado, el Ejecutivo tiene una supremacía general y por ende específica en el caso que nos atañe. Y el sustento de esta supremacía está en la confianza que el Parlamento otorga al Gobierno. Por el contrario, la pregunta que se hace el Tribunal en la STC 34/18 es cuál es el reparto de competencias que en materia presupuestaria establece nuestra Constitución. El sustento no se halla ahora en una supuesta confianza otorgada por un poder al otro sino en la Constitución misma, en concreto en su art. 134. A su vez, si la Constitución fija un sistema de reparto de competencias en materia presupuestaria es debido al carácter singular que tiene la Ley de Presupuestos. Así lo ha entendido el Tribunal en reiteradas ocasiones: «la Ley de Presupuestos es una norma singular por su vinculación inmediata con la propia función del Gobierno, a quien corresponde la dirección y orientación de la política económica, como afirmamos tempranamente en la STC 27/1981, de 20 de julio, (FJ 2), y hemos reiterado después en numerosas ocasiones [por todas, SSTC 76/1992, de 14 de mayo, FJ 4 a); 223/2006, de 6 de julio, FJ 5; y 206/2013, de 5 de diciembre]» (FJ6 STC 34/2018).

A modo de conclusión, estamos de acuerdo con Escribano López cuando afirma que «la norma que contiene la clave de todo el problema es una norma directamente relacionada con el Derecho Presupuestario, es decir, el ya citado art. 134.6 CE» (...) «El núcleo de la cuestión es una norma constitucional que sólo desde los principios presupuestarios puede ser correctamente entendida, al tiempo que se analizan con precisión las diversas competencias de Gobierno y Cámaras a lo largo del ciclo presu-

61 Escribano López, F. (2018), op.cit., p.161. 
puestario». La STC 34/18 comprende acertadamente que los «auténticos extremos constitucionales del problema son (...) estrictamente de derecho presupuestario» ${ }^{62}$.

\section{B) Contornos de la potestad del veto.}

Fijado este reparto de competencias, se puede proceder a analizar el art. 134.6 CE en concreto. Una vez clarificada la distribución de las competencias que en materia presupuestaria la Constitución establece entre el Ejecutivo y el Legislativo, que a su vez viene determinada por la singularidad de la ley de presupuestos, es posible entender la potestad gubernamental contenida en el art. 134.6 CE.

De este modo, en el fundamento jurídico séptimo, el Tribunal consagra de modo definitivo y suficiente el concreto alcance de la potestad de veto presupuestario. Para ello distingue cuatro aspectos, que procedemos a analizar a continuación: el alcance objetivo, el alcance temporal, la motivación del Gobierno y el procedimiento a seguir en el ejercicio de esta facultad gubernamental.

\section{Alcance objetivo y temporal.}

En primer lugar, en cuanto al alcance objetivo, la literalidad de la norma ciñe la prerrogativa del Ejecutivo tan sólo a los ingresos y gastos que estén efectivamente reflejados en los presupuestos, a aquellas medidas cuya incidencia sobre el Presupuesto del Estado sea real, efectiva y directa.

Con respecto al alcance temporal, «la conformidad del Gobierno ha de referirse siempre al Presupuesto en vigor en cada momento (ya sea el aprobado o el prorrogado), en coherencia con el principio de anualidad contenido en el mismo artículo». Puesto que la función del veto es precisamente salvaguardar el Presupuesto, el veto no podrá ejercerse con relación a presupuestos futuros, que aún no han sido elaborados por el Gobierno ni sometidos a la aprobación de la Cámara, sino tan sólo con respecto al Presupuesto actual o en curso, ya sea el aprobado o el prorrogado.

Pensamos que la STC 34/18 sigue en este punto la doctrina mayoritaria, pues aunque en principio distingue cuatro aspectos al hablar de los contornos de la facultad de veto (alcance material u objetivo, alcance temporal, motivación del Gobierno y procedimiento), entendemos que los dos primeros vienen a constituir conjuntamente lo que es el supuesto de hecho habilitante. Es decir, el Tribunal diferencia dentro del supuesto de hecho dos componentes inseparables pero distinguibles: de un lado el alcance objetivo o material, y de otro el alcance temporal. Deben darse los dos para que nos encontremos en una situación en la que el Gobierno puede ejercitar el veto;

62 Escribano López, F. (2017). «Los límites gubernamentales al ejercicio de la competencia legislativa por las Cortes: un supuesto de extralimitación del ejercicio de la competencia gubernamental». Revista española de derecho financiero, $\mathrm{n}^{\circ}$. 173, pp.17-20. 
el supuesto de hecho habilitante para el ejercicio del veto abarca ambos extremos: el objetivo o material y el temporal.

Precisamente la jurisprudencia más reciente ha resuelto distintos supuestos en los que faltaba al menos uno — sino los dos_ de estos dos elementos. Como vimos, en la STC 34/18 el Tribunal considera, por un lado, que el Ejecutivo no precisa que la iniciativa legislativa afecte a los ingresos presupuestados y, por otro, que la pérdida de ingresos es una mera hipótesis. Es decir, se trata de un caso de carencia de elemento objetivo.

Señalamos sumariamente los demás casos en lo que, por ausencia de alguno de los componentes que constituyen el supuesto de hecho habilitante, el Tribunal ha declarado un ejercicio ilegítimo de la facultad de veto por parte del Gobierno.

Las SSTC 44/18 de 26 de abril y 139/18 de 17 de diciembre resuelven casos en los que la iniciativa legislativa no afectaba sino de modo hipotético a los presupuestos en curso respectivos. Es decir, estamos también en dos casos en que no se reúne el primero de los requisitos: el alcance material u objetivo. En los escritos de disconformidad «el Gobierno no ha justificado de forma objetiva y suficiente que la proposición de ley implique aumento de créditos o diminución de ingresos del presupuesto en vigor, pues con su motivación el Gobierno no justifica que la proposición de ley en cuestión incida directamente en el presente curso» (FJ7 STC 44/18). El Tribunal considera que el Gobierno formula la supuesta afectación en términos de hipótesis, sin cumplir la exigencia de precisar adecuadamente las concretas partidas presupuestarias del presupuesto en vigor que se verían directamente afectadas por esa iniciativa legislativa, por lo cual no acredita el presupuesto habilitante del art. 134.6 CE.

La STC 94/18 por su parte es un claro ejemplo de la ausencia del requisito temporal. Reitera el Tribunal que el alcance temporal del veto presupuestario se refiere tan sólo al presupuesto en vigor, en coherencia con el principio de anualidad, «por lo que no podrá ejercerse por relación a presupuestos futuros». Con respecto a los «ejercicios plurianuales», el Tribunal reconoce la conexión temporal y lógica que existe entre los ejercicios presupuestarios de los diversos años, pero al mismo tiempo sentencia que dicha «conexión plurianual no desnaturaliza el carácter anual del presupuesto, por lo que el ejercicio de la potestad del art. 134.6 CE se restringe, igualmente, a la afectación de una medida al presupuesto del ejercicio en curso». Razona el Tribunal diciendo que la doctrina jurisprudencial ha fijado con claridad que el ámbito temporal de la aplicación de la potestad gubernamental se circunscribe exclusivamente al ejercicio presupuestario en curso. La decisión de aplicar la facultad del art. 134.6 CE a escenarios temporales posteriores al ejercicio en curso supone una aplicación extensiva de tal facultad que tiene una incidencia negativa en los derechos fundamentales de los parlamentarios. A este respecto es interesante señalar, tal como lo hace Giménez Sánchez, que la práctica de vetar iniciativas legislativas, aunque su entrada en vigor estuviera diferida a un ejercicio presupuestario futuro, no sólo era defendida por el Gobierno, sino que había sido avalada por un informe de la Oficina Presupues- 
taria del Congreso de los Diputados, con fundamento en la estabilidad presupuestaria $^{63}$.

Por su parte, la STC 17/19 es un caso de carencia de ambos elementos: objetivo y temporal, pues según el Tribunal la iniciativa legislativa afecta a un presupuesto futuro y la conexión que existe entre la misma y el Presupuesto es meramente hipotética.

\section{Motivación del Gobierno.}

Volviendo al análisis de la STC 34/2018, el Tribunal procede a analizar, en tercer lugar, la motivación que debe aportar el Gobierno. Ésta debe expresar la incidencia que la proposición o enmienda supone en los ingresos y gastos presupuestarios, precisando expresamente las concretas partidas presupuestarias que se verían afectadas.

Si bien de las sentencias del 2006 se podía extraer la conclusión de que, si el Gobierno se oponía, se presuponía iuris et de iure que se daba la afectación presupuestaria, de las últimas sentencias se puede deducir la posición contraria. La motivación del Gobierno debe ser exhaustiva, justificando de modo claro e indubitado que la presente iniciativa modifica los Presupuestos en curso, con lo que ello implica de desviación de la política económica del Ejecutivo.

Por tanto, la prerrogativa que la Constitución otorga al Gobierno podríamos calificarla de políticamente libre, pero nunca de jurídicamente libre. Es decir, para que el Gobierno pueda — si así lo considera libremente- ejercitar el veto, han de darse toda una serie de «requisitos sustantivos» ${ }^{64}$ que no son en modo alguno decidibles por el Gobierno, sino que son del todo objetivos. Una vez reunidas las condiciones que el art. 134.6 establece para que el Ejecutivo haga uso de tal facultad, éste es políticamente libre de ejercitarla o no. En este sentido ha de interpretarse la desafortunada expresión del Constitucional cuando afirma que el Gobierno dispone de un «amplio margen de apreciación que el Gobierno tiene en su estimación de si afecta o no, y en qué medida, a los ingresos y gastos de su presupuesto (FJ7 STC 34/18)». En modo alguno se da un margen de apreciación amplio sobre si la iniciativa afecta o no a los presupuestos, pues el hecho es del todo objetivo. El Gobierno posee un margen, en todo caso, en dos aspectos diversos pero no es este. El primero, en si hace uso de la prerrogativa que la Constitución le otorga, y en segundo lugar, y si decide ejercitarla, en el modo de justificar que está legitimado para ello pues en el presente caso concreto se produce la afectación presupuestaria requerida, es decir, en el contenido preciso de la motivación de la disconformidad gubernamental.

63 Giménez Sánchez, I. (2020), «Evolución de la doctrina del Tribunal Constitucional en materia de «veto presupuestario» del Gobierno», Revista Española de Derecho Constitucional, 118, p. 291.

64 Cfr. Escribano López, (2018). «Acerca del régimen jurídico constitucional de las proposiciones de ley que impliquen aumento de gasto o disminución de ingresos presupuestados (Un comentario a las SSTC 34/2018 y 44/2018)». Revista española de derecho financiero, n 180 , p. 186. 


\section{Procedimiento en el ejercicio del veto presupuestario.}

Por último, se examina el procedimiento a seguir en este caso. Entiende el Tribunal que a la Mesa le corresponde la función de calificación del criterio del Gobierno, como parte de la función genérica de calificación en relación con los documentos de índole parlamentaria que le remite el Gobierno. Esta función tiene un carácter técnico-jurídico y es limitada (no debe por tanto obstaculizar la facultad de veto; tal y como ya había señalado la STC 242/06). En concreto, debe pronunciarse sobre el carácter manifiestamente infundado del mismo, por lo que la Mesa podrá rechazar la falta de conformidad del Ejecutivo en aquellos casos en los cuales el Gobierno no ha concretado la afectación al Presupuesto. La Mesa debe comprobar que el veto encuentra efectivamente encaje en los contornos del art. 134.6 CE y que el impacto presupuestario es real y efectivo y no una mera hipótesis. Es decir, el Tribunal da un paso en el concreción de este concepto jurídico indeterminado (el carácter manifiestamente infundado), pues entiende que el criterio del Gobierno adolece de este defecto en el caso en el que «resulte evidente, a la luz de la propia motivación aportada por éste, que no se ha justificado la afectación de la iniciativa a los ingresos y gastos contenidos en el propio presupuesto». Entiende Escribano López que el Tribunal ha limitado drásticamente el alcance del control de la Mesa, pero ha dejado claro, por un lado, cuál es el objeto exacto de dicho control y por otro, que la disconformidad sólo procede en los supuestos de afectación al Presupuesto en ejecución ${ }^{65}$.

\section{C) Fallo.}

Una vez asentados con claridad los contornos del art. 134.6, es posible examinar si, en este caso concreto, la decisión de la Mesa ha producido un menoscabo de la competencia que se le otorga al Gobierno, es decir, se pronuncia sobre el fondo del conflicto de atribuciones. Para ello examina, en el fundamento jurídico octavo, la motivación exteriorizada por el Gobierno, y la motivación expresada por la Mesa.

El Tribunal concluye que «la decisión de la Mesa consistente en considerar que el Gobierno no justifica de forma objetiva y suficiente que dicha iniciativa implique aumento de créditos o disminución de ingresos del Presupuesto en vigor no ha producido un menoscabo de la competencia derivada del art. 134.6 CE» (FJ9). Y ello con base en dos razones. La primera, porque la motivación exteriorizada por el Gobierno se refiere a una pérdida eventual de ingresos procedentes del FSE, pues el Ejecutivo no ha precisado que la iniciativa legislativa afecte a los ingresos presupuestados. La segunda, puesto que el Gobierno no ha justificado de forma explícita la adecuada conexión entre la medida que se propone y los ingresos y gastos presupuestarios, pues la pérdida de ingresos es una mera hipótesis. «La conexión debe ser directa e inmediata, actual, y por tanto no meramente hipotética», sentencia el Tribunal. Con base

65 Escribano López, F. (2018); op.cit, p. 194. 
en ello, el Tribunal Constitucional desestima el presente conflicto entre órganos constitucional promovido por el Gobierno.

\section{CONCLUSIONES}

Pensamos que no es redundante decir, una vez más, que la STC 34/18, al contrario de las anteriores, contiene una satisfactoria jurisprudencia que podríamos calificar de suficiente y adecuada. Asimismo consideramos que esta jurisprudencia es fruto de un enfoque determinado, de una perspectiva concreta del artículo en cuestión que nos permite interpretarlo en su más profunda esencia y del modo más preciso. Todo precepto ha de ser interpretado, y esta interpretación depende de la perspectiva que el intérprete adopta, de su clave hermenéutica. ¿Podemos adivinar cuál es la clave hermenéutica que el Tribunal adopta desde la STC 34/18 en adelante? Como ya hemos demostrado, el Tribunal interpreta de modo adecuado el art. 134.6 CE porque entiende que se trata de una norma presupuestaria y como tal la comprende y analiza. Es decir, la primera de las conclusiones es ésta: la comprensión del veto presupuestario como una norma presupuestaria permite su correcta interpretación.

Por otro lado, podemos observar que el Tribunal entiende el art. 134.6 CE como una norma presupuestaria porque utiliza, expresa o implícitamente, los siguientes criterios interpretativos. En primer lugar, como el propio Tribunal afirma, realiza una interpretación literal del precepto. En el FJ7 de la STC 34/18 se puede leer: «La propia literalidad de la norma constitucional ciñe dicha potestad del Gobierno a los ingresos y gastos que estén efectivamente reflejados en el mismo Presupuesto» (...) «De acuerdo con la literalidad del art. $134 \mathrm{CE}$, y con el sistema de reparto de competencias que el mismo refleja, ya se ha hecho notar que el Gobierno podrá oponerse sólo en aquellos casos en los cuales la medida propuesta, enmienda o proposición, incida directamente en el citado Presupuesto. (...) Por ello, la misma se vincula y ciñe a los casos en los cuales una proposición de ley tenga incidencia directa e inmediata en el plan presupuestario en vigor, lo que significa, como deriva de la propia literalidad del art. 134.6 CE, que implique razonablemente un incremento de los créditos o una disminución de los ingresos en el mismo ejercicio presupuestario.

En segundo lugar, interpreta el precepto de un modo sistemático. La interpretación sistemática nos habla de la importancia de interpretar cada precepto como parte de un todo, en su contexto y dentro de su ámbito. Como ya desarrollamos, pensamos que cuando el Tribunal, en el FJ7 de la STC 34/2018 expone la doctrina sobre el reparto de competencias presupuestarias entre el Ejecutivo y el Legislativo, está interpretando el art. 134.6 como un apartado del art.134 y éste a su vez como un artículo que se inserta en el apartado VII de la CE (cuya rúbrica es: «Economía y Hacienda»). Como ya explicamos, el Tribunal entiende que la facultad de veto es una norma que sólo se comprende si atendemos a las particularidades que la Constitución concede de la Ley de Presupuestos y que se reflejan en el art. 134 CE. Este artículo contiene la 
doctrina constitucional sobre el ciclo presupuestario, y cada uno de sus apartados han de interpretarse en clave presupuestaria.

Por último, la interpretación teleológica hace referencia al fin de la norma, que no es otro que el preservar el Presupuesto, como instrumento principal al servicio de la acción del Gobierno, tal y como afirma el mismo Tribunal: «lo determinante es la función misma que cumple el Presupuesto como herramienta para el desempeño de la labor que constitucionalmente le está atribuida al Gobierno en el art. 97 CE. Por ello, en suma, la función del art. 134.6 CE es salvaguardar la propia función del Presupuesto; de ahí que la potestad contenida en el art. 134.6 CE deba entenderse como un mecanismo que consiente al Gobierno defender su legítimo ámbito de actuación constitucionalmente previsto» (FJ7 STC 34/18).

Pensamos que la doctrina constitucional contenida en la reciente jurisprudencia del Tribunal es el producto del conjunto de estos tres criterios interpretativos ${ }^{66}, y$ cuyo resultado es la comprensión del veto presupuestario como una norma de Derecho Presupuestario.

De este modo, el Tribunal ha llevado a cabo una adecuada labor interpretativa, lo que contribuye al ya mentado freno al uso abusivo de la facultad y, secundariamente, al restablecimiento de la adecuada relación entre el Legislativo y el Ejecutivo, preservando el Estado de Derecho. Así pues, nuestro Alto Tribunal, además de intérprete supremo (art. 1 LOTC), «se erige en árbitro de las grandes cuestiones que dividen y enfrentan a los actores políticos» siendo «asimismo un factor de cohesión, de integración y de pacificación de la sociedad política» ${ }^{67}$.

Si el Tribunal Constitucional ya ha llevado a cabo su aportación a través de su jurisprudencia, es la hora del legislativo, pues bien escaso resulta el desarrollo legislativo del art. 134.6 CE que contienen los artículos 111 y 126.2 RC. Es menester una regulación que, además de recoger esta doctrina jurisprudencial, tenga en cuenta las profundas modificaciones que con respecto al ciclo presupuestario se derivan de la modificación del art. $135 \mathrm{CE}^{68}$ y de la participación de nuevos actores en el mismo, entre ellos la Comisión Europea y la Autoridad independiente de responsabilidad fiscal (AIREF) ${ }^{69}$.

66 Aunque restringido al alcance temporal del veto, Giménez Sánchez, I. también afirma que el Tribunal realiza una interpretación literal, sistemática y teleológica del precepto que le lleva a reconocer el principio de anualidad presupuestaria como criterio para determinar el alcance temporal del veto gubernamental. Giménez Sánchez, I. (2020), op.cit., p. 292.

67 Dermizaky, P. (2019). "Justicia constitucional y democracia», en Anuario Iberoamericano de Justicia Constitucional, nº 1 , p. 219.

68 Escribano López, F. (2018) op.cit., p. 178.

69 Cfr. Ruiz Almendral, V. (2018). «El presupuesto del Estado: una (re)visión constitucional». Revista española de Derecho Financiero, nº179, p.120. 
Title:

The curb of the Constitutional Court to the abuse of the budget veto: analysis of the constitutional jurisprudence in the art. 134.6 Spanish Constitution.

\section{Summary:}

I. Introduction. II. Brief approximation to the constitutional legal regime of the budget veto. III. Analysis of the constitutional jurisprudence in the art. 134.6 Spanish Constitution: from a deficient exegesis to a sufficient one. IV. Conclusions.

\section{Resumen:}

Este artículo trata de analizar la jurisprudencia dimanada de nuestro Alto Tribunal en torno al art. 134.6 CE. Este apartado del art. $134 \mathrm{CE}$ constitucionaliza la facultad que ostenta el Gobierno de no prestar su consentimiento a la tramitación de proposiciones de ley que conlleven una afectación presupuestaria.

Tras una breve exposición sobre el régimen jurídico del veto presupuestario, se procede a analizar cada una a una de las sentencias emanadas del Alto Tribunal. Dada la función de intérprete supremo que el Tribunal Constitucional ostenta, su jurisprudencia podría incluso llegar a influir en determinadas decisiones políticas. En el presente caso, una interpretación del art. 134.6 CE «pro gobierno» podría haber contribuido — si además confluyen unas determinadas circunstancias políticas - a una utilización del veto como un instrumento político, tal y como ha sucedido en la XII legislatura. En sentido contrario, una interpretación adecuada del precepto - que entendemos se da a partir de la STC 34/18 - supondría un freno a dicho uso politizado de la facultad de veto presupuestario que posee el Gobierno.

Pensamos que ésta última sentencia enmarca acertadamente el art. 134.6 CE. De dicho enfoque deriva una interpretación constitucional de la facultad de veto presupuestario adecuada y completa. Esta interpretación parte de la singularidad que la Constitución otorga a la ley de presupuestos, y podría frenar el uso abusivo del mismo.

\section{Abstract:}

This article intends to analyze the jurisprudence arising from the Spanish Constitutional Court in the art. 134.6 of the Spanish Constitution. This section of art. 134 constitutionalizes the power of the Government not to give its consent to the processing of proposals for laws that entail budgetary effects.

After a briefing on the legal regime of the budget veto, we proceed to analyze each one of the sentences issued by the High Court. Given the role of supreme interpreter that the Constitutional Court holds, its jurispru- 
dence could even influence certain political decisions. In the present case, an interpretation of art. 134.6 EC «pro government» could have contributed -if certain political circumstances also converge - to using the veto as a political instrument, as has happened in the XII legislature. On the contrary, an adequate interpretation of the precept — which we understand is given from STC 34/18 - would be a crub on this politicized use of the budget veto power that the Government has.

We think that this last sentence correctly frames art. 134.6 CE. From this approach derives a constitutional interpretation of the power of adequate and complete budget veto. This interpretation starts from the singularity that the Constitution grants to the budget bill, and could stop the abusive use of it.

\section{Palabras clave:}

Veto presupuestario, interpretación constitucional, Tribunal Constitucional, uso abusivo.

Key words:

Budget veto, constitutional interpretation, Constitutional Court, abusive use. 
